\title{
East Pacific ocean eddies and their relationship to subseasonal variability in Central American wind jets
}

\author{
Chueh-Hsin Chang, ${ }^{1,2}$ Shang-Ping Xie, ${ }^{1,3}$ Niklas Schneider, ${ }^{3,4}$ Bo Qiu, ${ }^{4}$ Justin Small, ${ }^{5}$ \\ Wei Zhuang, ${ }^{6}$ Bunmei Taguchi, ${ }^{7}$ Hideharu Sasaki, ${ }^{7}$ and Xiaopei Lin ${ }^{8}$ \\ Received 23 May 2011; revised 18 August 2012; accepted 21 August 2012; published 2 October 2012.
}

[1] Subseasonal variability in sea surface height (SSH) over the East Pacific warm pool off Central America is investigated using satellite observations and an eddy-resolving ocean general circulation model. SSH variability is organized into two southwest-tilted bands on the northwest flank of the Tehuantepec and Papagayo wind jets and collocated with the thermocline troughs. Eddy-like features of wavelength $\sim 600 \mathrm{~km}$ propagate southwestward along the high-variance bands at a speed of $9-13 \mathrm{~cm} / \mathrm{s}$. Wind fluctuations are important for eddy formation in the Gulf of Tehuantepec, with a recurring interval of 40-90 days. When forced by satellite wind observations, the model reproduces the two high-variance bands and the phase propagation of the Tehuantepec eddies. Our observational analysis and model simulation suggest the following evolution of the Tehuantepec eddies. On the subseasonal timescale, in response to the gap wind intensification, a coastal anticyclonic eddy forms on the northwest flank of the wind jet and strengthens as it propagates offshore in the following two to three weeks. An energetics analysis based on the model simulation indicates that besides wind work, barotropic and baroclinic instabilities of the mean flow are important for the eddy growth. Both observational and model results suggest a re-intensification of the anticyclonic eddy in response to the subsequent wind jet event. Off Papagayo, ocean eddy formation is not well correlated with local wind jet variability. In both the Gulfs of Tehuantepec and Papagayo, subseasonal SSH variability is preferentially excited on the northwest flank of the wind jet. Factors for this asymmetry about the wind jet axis as well as the origins of wind jet variability are discussed.

Citation: Chang, C.-H., S.-P. Xie, N. Schneider, B. Qiu, J. Small, W. Zhuang, B. Taguchi, H. Sasaki, and X. Lin (2012), East Pacific ocean eddies and their relationship to subseasonal variability in Central American wind jets, J. Geophys. Res., 117, C10001, doi:10.1029/2011JC007315.

\section{Introduction}

[2] Central America separates the East Pacific warm pool to the west and the Caribbean Sea/Gulf of Mexico to the east.

\footnotetext{
${ }^{1}$ Department of Meteorology, School of Earth Science and Technology, University of Hawai'i at Mānoa, Honolulu, Hawai'i, USA.

${ }^{2}$ Research Center for Environmental Changes at Academia Sinica, Taipei, Taiwan.

${ }^{3}$ International Pacific Research Center, University of Hawai'i at Mānoa, Honolulu, Hawai'i, USA.

${ }^{4}$ Department of Oceanography University of Hawai'i at Mānoa, Honolulu, Hawai'i, USA.

${ }^{5}$ Climate and Global Dynamics Division, National Center for Atmospheric Research, Boulder, Colorado, USA.

${ }^{6}$ State Key Laboratory of Tropical Oceanography, South China Sea Institute of Oceanology, Chinese Academy of Sciences, Guangzhou, China. ${ }^{7}$ Japan Agency for Marine-Earth Science and Technology, Yokohama, Japan.

${ }^{8}$ Physical Oceanography Laboratory, Ocean University of China, Qingdao, China.

Corresponding author: C.-H. Chang, Research Center for Environmental Changes at Academia Sinica, PO Box 1-48, Taipei 11529 , Taiwan. (shingchang@gate.sinica.edu.tw)

C2012. American Geophysical Union. All Rights Reserved. 0148-0227/12/2011JC007315
}

During November to April, the northeasterly winds prevail on both sides of the Central American Isthmus (Figure 1a). In winter, frequent formation of the cold fronts over the North American continent sometimes extends far south into Mexico and Central America. The mean penetration latitudes are $12^{\circ}-14^{\circ} \mathrm{N}$ [Reding 1992; Steenburgh et al., 1998]. The Sierra Madre and the Central American Cordillera mountain ranges of 1-4 km high block the winds associated with both the prevailing trades and cold front incursions, producing intense wind jets at three major mountain gaps over the Gulfs of Tehuantepec, Papagayo, and Panama. Such a strong wind event is referred to as gap wind event. Tehuantepec gap wind $\left(16^{\circ} \mathrm{N}\right)$ is mainly midlatitude-originated, whereas the two lower-latitude Papagayo and Panama gap winds $\left(12^{\circ} \mathrm{N}\right.$ and $8^{\circ} \mathrm{N}$, respectively) (Figure 1a) have stronger tropical influences such as the Caribbean trade winds, Central American monsoon, and tropical storms [Chelton et al., 2000a, 2000b; Xie et al., 2005]. The Tehuantepec wind jet can reach $25 \mathrm{~m} / \mathrm{s}$ in speed [Roden, 1961; McCreary et al., 1989; RomeroCenteno et al., 2003]. The Papagayo and Panama gap winds are generally weaker. The Central American gap winds diminish toward summer but slightly strengthen during the Central American midsummer drought period of July-August 

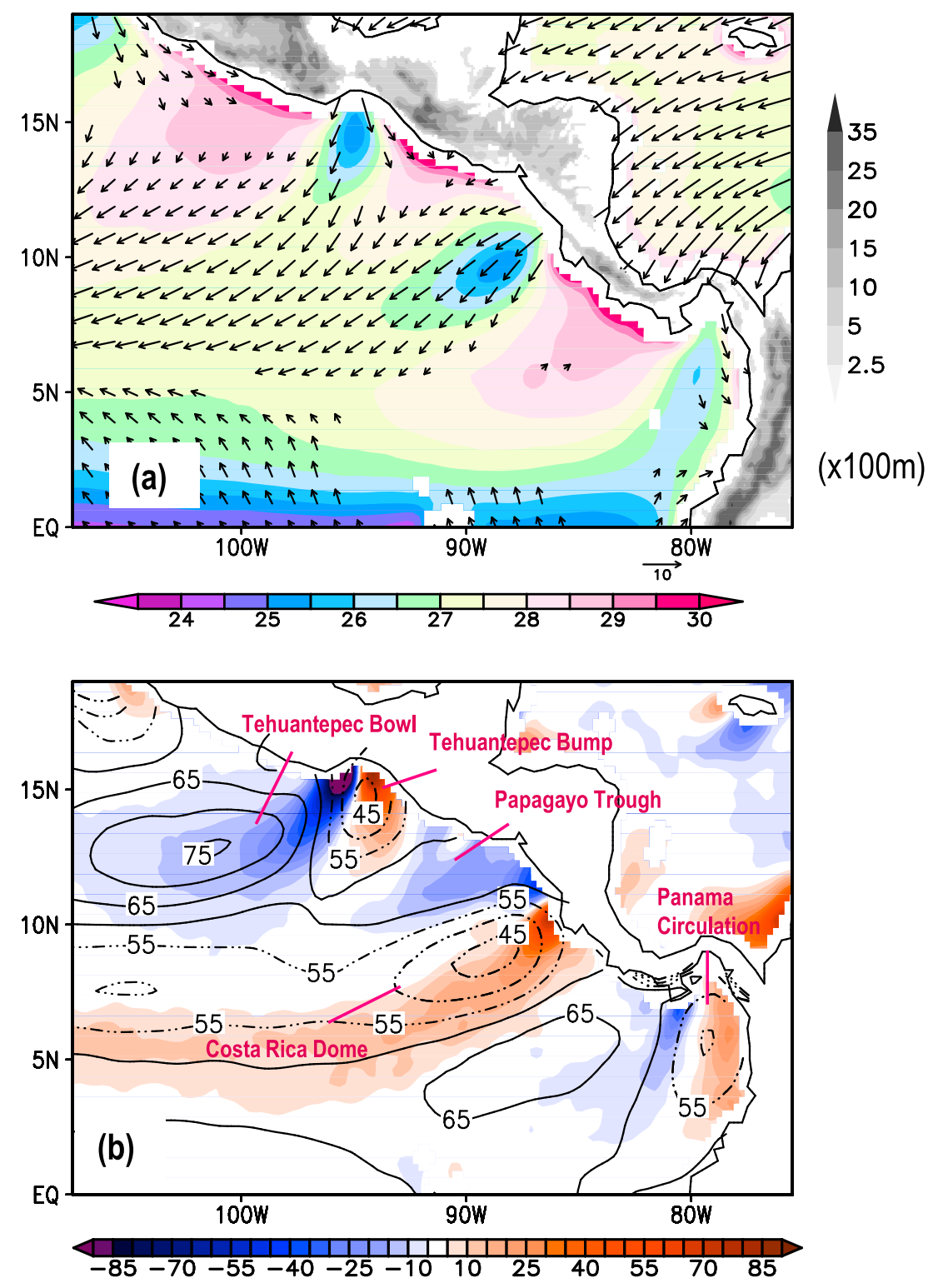

Figure 1. Winter (December-March) climatology. (a) Wind velocity (vector; $\mathrm{m} / \mathrm{s}$ ), SST (color, ${ }^{\circ} \mathrm{C}$ ), and orography ( $\geq 2500 \mathrm{~m}$ in gray shading). (b) Wind stress curl (color; $10^{-8} \mathrm{~N} / \mathrm{m}^{3}$ ) and SSH (contour; $\mathrm{cm}$ ). The contour interval is $5 \mathrm{~cm}$. The main features in the winter mean ocean circulation are labeled in Figure $1 \mathrm{~b}$.

[Magaña et al., 1999; Small et al., 2007], associated with the westward expansion of the Azores-Bermuda high [RomeroCenteno et al., 2007]. The summer gap winds are much weaker and infrequent [Trasviña and Barton, 2008; Liang et al., 2009].

[3] For the annual mean and seasonal cycle, the thermocline depth response to the gap winds is, to first order, consistent with linear Sverdrup dynamics [Kessler, 2002, 2006]. Figure 1 shows the climatological wind, sea surface temperature (SST), wind stress curl and the sea surface height (SSH) in the East Pacific warm pool during the winter months of December-March. Cold SSTs are seen along three gap wind jets (Figure 1a). In response to wind curl dipoles of the wind jets, the winter mean ocean circulation features the Tehuantepec Bowl, the Tehuantepec bump [Kessler, 2006], the Papagayo Trough, the Costa Rica Dome, and the Panama circulation (Figure 1b).

[4] On shorter time scales, the East Pacific warm pool is characterized by meso-scale eddy activities [Kessler, 2006; Willett et al., 2006] and strong subseasonal variability (50-100-day) in SSH [Perigaud, 1990; Giese et al., 1994; Farrar and Weller, 2006]. Meso-scale eddies are often generated in the gap-wind regions [Clarke, 1988; Barton et al., 1993; Trasviña et al., 1995]. Some are long-lived and can travel thousands of kilometers westward along the shear zone between the North Equatorial Current $\left(\mathrm{NEC} \sim 11^{\circ}-13^{\circ} \mathrm{N}\right)$ and North Equatorial Countercurrent (NECC $\sim 5^{\circ}-10^{\circ} \mathrm{N}$ ) [Giese et al., 1994; Farrar and Weller, 2006]. Eddies off Central America are several hundred kilometers in diameter, much larger than the radius of deformation $(80-150 \mathrm{~km})$ [Chelton et al., 1998]. They typically propagate southwestward, with 
SSH anomalies of $10-30 \mathrm{~cm}$ or equivalently thermocline displacements of 60-145 m [Chelton et al., 1998; Müller-Karger and Fuentes-Yaco, 2000; Trasviña et al., 2003; Willett et al., 2006]. A systematic census of the long-lived Tehuantepec and Papagayo eddies (of lifetime $\geq 4$ weeks) reports that every year there are approximately 6 eddies of lifetime varying from 12 to 20 weeks on average during the eddy season [Palacios and Bograd, 2005]. The interannual variability is also obvious in these long-lived eddy activities. The southwest propagation may relate to the internal dynamics of the eddy [Trasviña et al., 2003].

[5] The ocean response to gap wind fluctuations has been investigated using analytical and numerical models. Windinduced eddies in the models of Clarke [1988], McCreary et al. [1989], and Umatani and Yamagata [1991] are weaker than those in observations. To account for this discrepancy, Hansen and Maul [1991] propose instability of the northward Costa Rica Coastal Current (CRCC) as an alternative mechanism for eddy generation. Barton et al. [1993] suggest that successive gap wind events may be a key factor. In particular, it is common to observe temporal clustering of cold surge events in Central America [Reding, 1992; Colle and Mass, 1995; Schultz et al., 1998]. In addition, coastal Kelvin wave instability is proposed for coastal eddy formation during 1997 when wind jets are weak [Zamudio et al., 2006].

[6] Anticyclonic eddies are stronger with a longer lifetime than cyclonic ones in the East Pacific warm pool [Stumpf and Legeckis, 1977; Crépon and Richez, 1982; McCreary et al., 1989; Barton et al., 1993; Trasviña et al., 1995; Müller-Karger and Fuentes-Yaco, 2000; Gonzalez-Silvera et al., 2004; Palacios and Bograd, 2005]. Willett et al. [2006] review various mechanisms for this asymmetry. Umatani and Yamagata [1991] explain the dominance of anticyclonic eddies in terms of inviscid nonlinear, intermediate geostrophic dynamics while studies using 1.5-layer [McCreary et al., 1989] and 2.5-layer nonlinear models [Lee, 1990] suggest that entrainment mixing preferentially damps the cyclonic eddy forced by upwelling. With the size and strength of the wind jet typical to the region, nonlinear Ekman pumping can also contribute to anticyclonic eddy dominance, due to the positive feedback between the anticyclonic vorticity and Ekman pumping [Thomas and Rhines, 2002]. The resultant sharper horizontal temperature gradient on the downwelling flank of the wind jet can further reinforce such an asymmetry.

[7] The Tehuantepec wind jet is asymmetric about the jet axis. The jet follows an inertial circle, turns clockwise after leaving the coast [Clarke, 1988; Schultz et al., 1997a, 1997b; Steenburgh et al., 1998], gradually adjusts to near-geostrophic balance and becomes easterly [Chelton et al., 2000b]. The clockwise turning of the Tehuantepec gap wind causes larger Ekman downwelling on the northwestern flank of the wind jet than upwelling on the southeastern flank. This asymmetry in Ekman pumping could be an additional mechanism for the preference of anticyclonic eddies in the ocean.

[8] The Central American gap winds and their effects were discussed briefly in Wyrtki's [1966] review of surface ocean circulation for eastern equatorial Pacific. These wind jets are now recognized as important in driving the seasonal mean upper ocean circulation [Kessler, 2002, 2006]. As pointed out in Kessler's [2006] review paper, the smooth feature in the ocean current observation, as compared to the result of the linear Rossby wave model, is likely due to gap wind- induced eddy mixing that is not represented in the model. In the past, in situ measurements reveal the subsurface structures of the wind-generated eddies following the onset of individual gap wind events [McCreary et al., 1989; Barton et al., 1993; Trasviña et al., 2003; Barton et al., 2009]. Studies using satellite observations of SSH, SST and ocean color give a valuable kinematic description of eddy characteristics, including long lifetime of some anticyclonic eddies (up to a few months), and their long travel distance (some $1500 \mathrm{~km}$ away from the coast) [Müller-Karger and Fuentes-Yaco, 2000; Gonzalez-Silvera et al., 2004; Palacios and Bograd, 2005; Willett et al., 2006], forming the basis for further dynamical research. Important questions remain to be fully addressed: to what extent does the wind variability, including the temporal clustering of gap wind events, explain the eddy formation and subsequent growth in the gap wind regions? What determines the southwest propagation of eddies? How well can models forced with realistic wind capture the fundamental characteristics of gap wind eddies?

[9] Advance in ocean observations now permits and calls for a systematic investigation into these questions. Satelliteborne microwave sensors have accumulated records for a decade or longer of surface wind stress, SSH, and SST of sufficient resolution and coverage in space and time. Eddy activities in the East Pacific warm pool are of time scales ranging from synoptic to subseasonal timescales, difficult to cover with in situ observations over a large area.

[10] The present study investigates subseasonal variability in the East Pacific warm pool off Central America by synthesizing a suite of satellite observations for the past decade that include many realizations of eddy formation. Our analysis reveals that there are two distinct bands of subseasonal variability in $\mathrm{SSH}$, on the northwest flanks of the Tehuantepec and Papagayo jets, respectively. Our statistical analysis of long observations shows that wind fluctuations are the major mechanism for eddy formation off Tehuantepec, consistent with previous studies [Stumpf and Legeckis, 1977; Clarke, 1988; McCreary et al., 1989; Barton et al., 1993; Trasviña et al., 1995; Thomas and Rhines, 2002; Trasviña et al., 2003] that have focused on a few individual events. Off Papagayo, by contrast, eddy genesis is more complicated and not highly correlated with wind fluctuations. To study eddy generation mechanisms, we use simulations by an eddyresolving ocean general circulation model (OGCM). The model succeeds in simulating Tehuantepec eddy formation when high-resolution satellite wind data are used as forcing. The model results show importance of mean flow instabilities in energizing eddies.

[11] The rest of the paper is organized as follows. Section 2 describes the data and model. Sections 3 and 4 examine subseasonal variability in the gap wind regions, using satellite observations and model simulations, respectively. Section 5 examines other important aspects of ocean subseasonal variability and discusses the origin of wind variability. Section 6 is a summary with some general remarks on orographic forcing of subseasonal variability.

\section{Data and Model}

[12] We use the weekly averaged QuikSCAT vector wind at $10 \mathrm{~m}$ height assuming neutral stratification [Wentz and Smith 1999] on a $0.25^{\circ} \times 0.25^{\circ}$ grid from 21 July 1999 to 

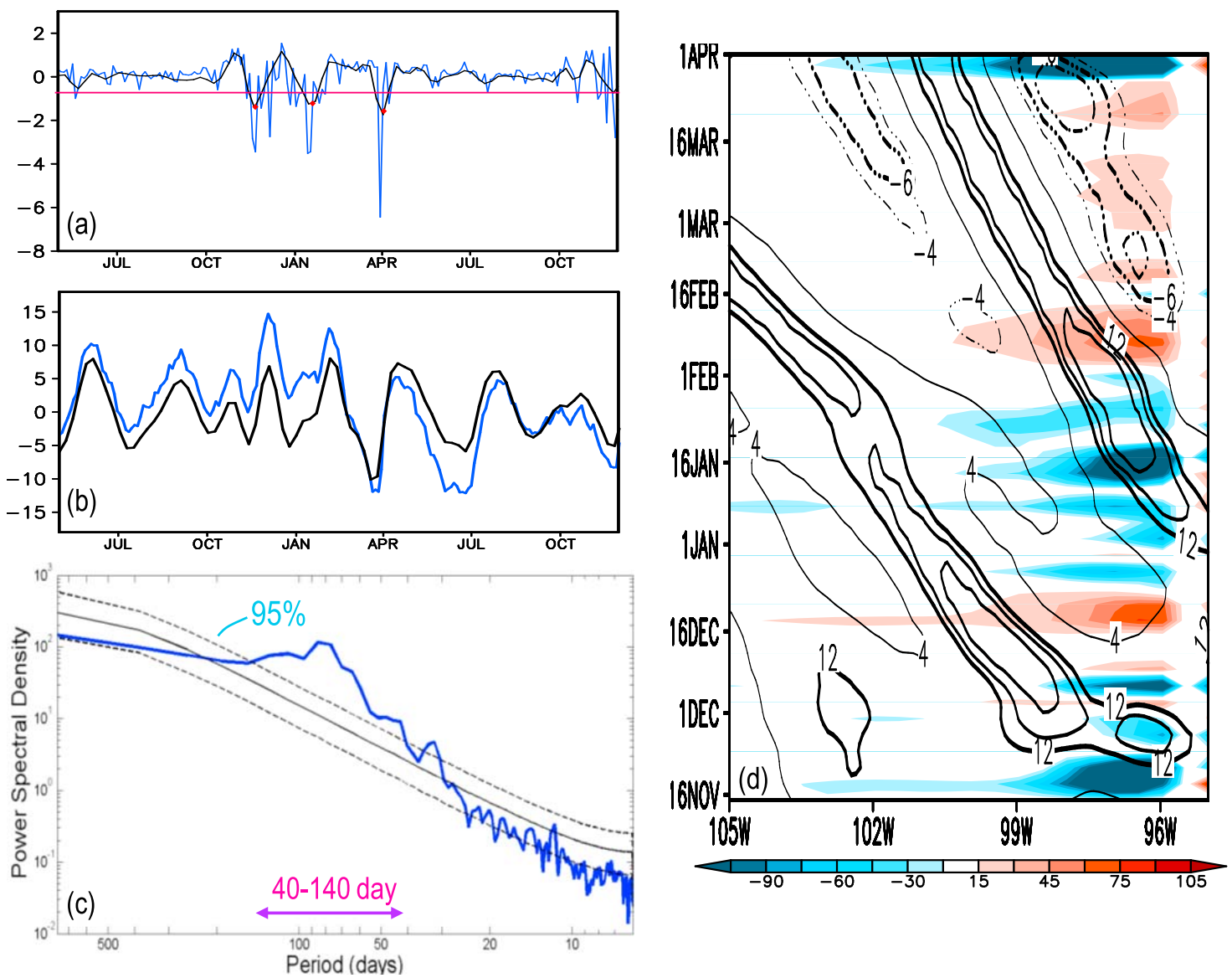

Figure 2. Time series of the 3-daily (blue) and 20-120 days filtered (black) (a) meridional wind stress, $\tau_{\mathrm{y}}$, and (b) SSH anomalies at Tehuantepec (Figures $4 \mathrm{a}$ and $4 \mathrm{~b}$ ) from the OFES QSCAT run for May 2002Nov 2003. In Figure 2a, the horizontal pink line is drawn at $-0.75 \sigma$ of the subseasonal $\tau_{\mathrm{y}}$ anomaly; red squares mark the strong subseasonal gap wind events that are selected for the composite analysis in section 4.1. (c) Power spectrum for July 22 1999-December 302006 of 3-daily SSH. The seasonal cycle is removed. The solid black line corresponds to the theoretical spectrum for a first-order autoregressive process with the same statistics as the model time series, and the dashed lines correspond to the 5th and 95th percentile confidence levels (see text for details). (d) Time-distance diagram of 3-daily SSH (cm; contour) and wind stress curl $\left(\times 10^{-8} \mathrm{~N} / \mathrm{m}^{3}\right.$; color $)$ anomalies for Nov 2002-April 2003 along the HV band of Tehuantepec. The contour levels start at +12 and $-6 \mathrm{~cm}$ for the positive and negative SSHA, respectively. The contour interval for SSHA is $2 \mathrm{~cm}$. Relatively thin contour lines of $\pm 4 \mathrm{~cm}$ are also shown to ensure inclusion of important SSH signals.

8 November 2006. The QuikSCAT data are produced by Remote Sensing Systems and sponsored by the NASA Ocean Vector Winds Science Team. Satellite altimeters measure SSH deviations from the mean geoid. We use the weekly SSH anomaly maps from the Archiving, Validation and Interpretation of Satellite Oceanographic Data (AVISO) [Ducet et al., 2000] from 14 October 1992 to 07 June 2006. The AVISO SSH anomalies are combined data product merged from the TOPEX/Poseidon, Jason, and the European Remote Sensing satellites (ERS-1/2) and mapped on global irregular grid with about $1 / 3^{\circ}$ spacing. The merged product improves spatial and temporal resolution compared to using one single altimeter [Ducet et al., 2000]. To obtain the absolute SSH, we added the AVISO SSH anomaly to a sea level climatology, computed using near-surface velocity derived from surface drifter data and satellite altimeter observations
[Niiler et al., 2003; Maximenko et al., 2009]. The Niiler and Maximenko climatology represents the mean SSH field over the period 1992-2002. For the SST, we use the weekly $0.25^{\circ} \times 0.25^{\circ}$ gridded SST product from The Tropical Rainfall Measuring Mission (TRMM) Microwave Imager (TMI) [Wentz et al., 2000] for the period 10 December 199714 February 2007. To map planetary-scale atmospheric patterns, we use the European Center for Medium-range Weather Forecasting re-analysis (ERA-40) [Uppala et al., 2005]. Daily geopotential height on a $1^{\circ} \times 1^{\circ}$ grid is processed into weekly mean value for 1 January 1989-27 December 2006.

[13] To study eddy generation mechanism, we use simulations by the OGCM for the Earth Simulator (OFES), an eddy-resolving ocean model based on the Geophysical Fluid Dynamics Laboratory (GFDL) Modular Ocean Model version 3. The horizontal resolution is $0.1^{\circ} \times 0.1^{\circ}$. There are 

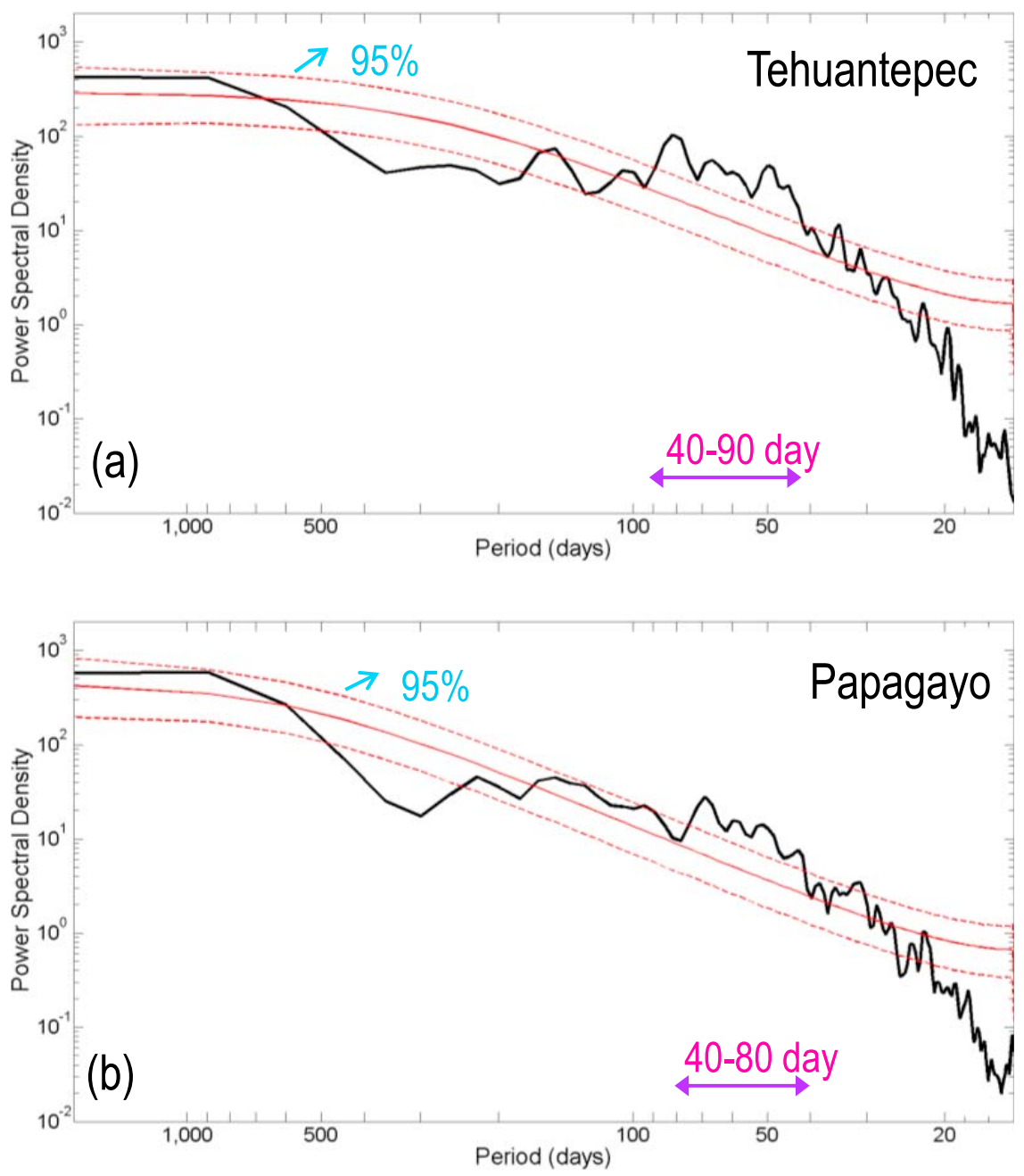

Figure 3. Power spectrum of the reference time series of the satellite weekly SSH (see Figure 4b) for (a) Tehuantepec, and (b) Papagayo from 14 Oct 1992 to 7 June 2006. The seasonal cycle is removed but the time series is otherwise unfiltered. The solid red line corresponds to the theoretical spectrum for a firstorder autoregressive process with the same statistics as the observed time series, and the dashed red lines correspond to the 5th and 95th percentile confidence levels.

54 vertical levels, with $5 \mathrm{~m}$ spacing near the surface [Masumoto et al., 2004; Sasaki et al., 2008]. Following a 50 -year spin-up, two hindcast runs are carried out. One (the NCEP run hereafter) is forced by the National Centers for Environmental Prediction (NCEP) reanalysis daily product of wind stress, heat and salinity fluxes for 1950-2004. The NCEP reanalysis forcing is on a $2^{\circ} \times 2^{\circ}$ Gaussian grid.

[14] The other hindcast (the QSCAT run) is otherwise the same except the use of daily QuikSCAT wind stress forcing from 20 July 1999 to the end of 2006 [Sasaki et al., 2008]. The QSCAT wind stress is taken from Japanese Ocean Flux data sets with Use of Remote sensing Observation (J-OFURO) [Kubota et al., 2002], constructed with a weighted mean method of $1^{\circ}$ horizontal resolution. This is a substantial improvement over the NCEP forcing, a model analysis with an effective resolution of $6^{\circ}$. The OFES QSCAT run captures narrow-scale ocean features and their variability [Sasaki et al., 2006], such as the Hawaiian Lee Countercurrent [Sasaki and Nonaka 2006; Sasaki et al., 2010] and biological activity in the eastern tropical Pacific off Central America [Sasai et al., 2007].
[15] The ocean is known to be an integrator that responds more effectively to the lower-frequency synoptic atmospheric forcing than to higher-frequency forcing [Yoshida et al., 2010]. In the Central American gap wind regions, the observed large energetic eddies are likely to be spun up by successive gap wind events [Barton et al., 1993]. In Figure $2 \mathrm{a}$, the time series of the daily QSCAT meridional wind stress (in blue) between mid-November 2002 and early February 2003 provides examples of consecutive synoptic gap wind events. We first identify the dominant frequencies of the SSH variability with the seasonal cycle removed. The power spectrum of the daily SSH anomalies sampled every three days (called 3-daily SSH hereafter) from the OFES QSCAT run in the Gulf of Tehuantepec shows that the significantly elevated power only occurs at timescales between 40 and 140 days. The power decreases rapidly for periods $<30$ days (Figure $2 \mathrm{c}$ ). The time series of both the 3 -daily $\mathrm{SSH}$ and the SSH anomalies filtered with a 20-120 days bandpass filter show pronounced variability at the same subseasonal time scales (Figure 2b). Likewise, the spectra of unfiltered $\mathrm{SSH}$ anomalies from satellite altimetry shows 

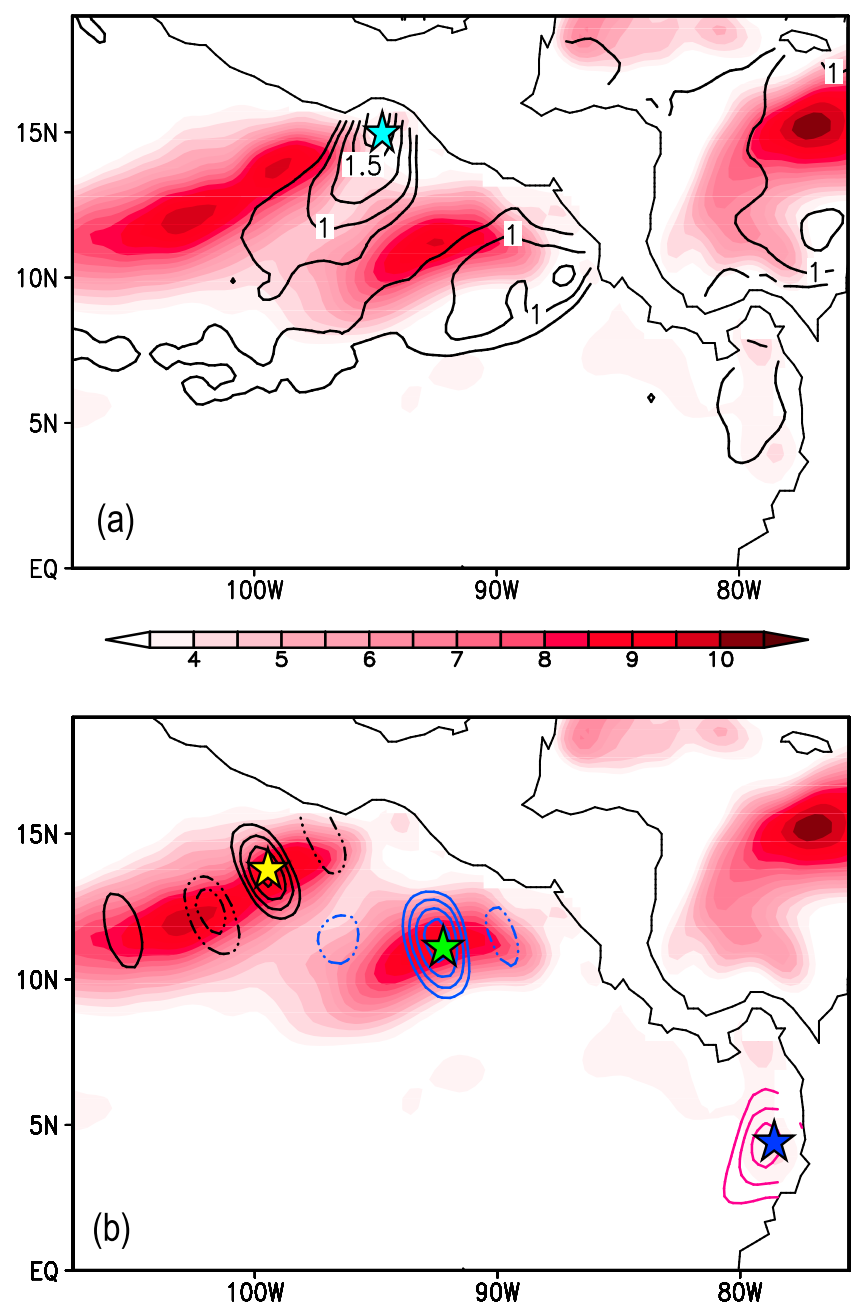

Figure 4. (a) The standard deviation $(\sigma)$ of wind speed $(\mathrm{m} / \mathrm{s}$; contour) and SSH (cm; color) anomalies for DecemberMarch. The contour interval for wind speed $\sigma$ is $0.25 \mathrm{~m} / \mathrm{s}$. The star indicates the action center for subseasonal wind speed anomaly. (b) SSHA correlation coefficient (contour) with respect to SSHA time series at action centers (marked as stars) in three regions of high variance, superimposed on SSHA $\sigma(\mathrm{cm}$; color) for December-March. The contour levels start at \pm 0.35 with an interval of 0.15 for Tehuantepec and Papagayo gap wind regions, while they start at \pm 0.7 with an interval of 0.1 for Panama region. The time period used for this analysis is 1999-2005 for wind speed anomaly, and 1993-2005 for SSHA, respectively.

enhanced variability in the bands of 40-90 days and 4080 days in Tehuantepec and Papagayo, respectively (Figure 3 ). (See detailed discussion of the similarity between the OFES QSCAT run and observations in section 4). For the power spectrum estimates, we use the unfiltered SSH with seasonal cycle removed. To reduce the noise level, we apply Welch's method [Welch, 1967]. We assess statistical significance with respect to a first-order autoregressive (AR(1)) process by generating 10,000 synthetic $\operatorname{AR}(1)$ time series with the same statistical properties as the true time series, calculating the power spectra in the same way, and then identifying the 95th percentile of the synthetic time series power spectra.
[16] Furthermore, Figure 2d shows the synoptic SSH and wind stress curl anomalies along the high SSH variance band of Tehuantepec (see Figure 4) during the gap wind season 2002-2003. It reveals the ocean response to synoptic atmospheric forcing: a prolonged sequence of synoptic gap wind events, such as the events from mid-November to early December, and from early January to early February, gives rise to long lasting $\mathrm{SSH}$ signals, whereas a single isolated wind event, as occurred during December 3-9 yields a less robust SSH response (Figure 2d). In view of the importance of synoptic gap wind events clustered on subseasonal timescales, in this study, we focus on subseasonal variability of the SSH response to a succession of synoptic gap wind events, whose amplitude modulates on subseasonal timescales. As seen in Figure 2d, a subseasonal gap wind event represents a cluster of synoptic gap wind events, and typically lasts about 3-4 weeks (see also Figure 2a, black curve), as will be seen more clearly in the composite analysis (sections 3 and 4).

[17] To conform to satellite altimeter data, weekly mean data are used in diagnosing observations and model output. The seasonal cycle is removed by subtracting the monthly climatology (with a temporal interpolation to weekly intervals). A 20-120-day band-pass filter is applied to suppress high frequency disturbances such as synoptic noises and eddies of shorter timescales, and to remove low frequency variability such as El Niño Southern Oscillation. The frequency band is broad enough to include the atmospheric Madden-Julian Oscillation and capture eddy shedding events of a typical interval of 40-90 days off Central America. Most of our analysis focuses on the winter season from November to March when the gap winds are strongest. We define the 20-120-day bandpass filtered data with seasonal cycle removed to be the subseasonal anomaly in our study.

\section{Observations}

[18] Figure 4a shows the standard deviations $(\sigma)$ of 20 120 day band-pass filtered variability in SSH and wind speed during December-March 1993-2005 for SSH and 1999-2005 for wind speed, both based on satellite observations. The bandpass filtered SSH variability during 1993-2005 is nearly identical to that during 1999-2005. Two high SSH-variance (HV; $\sigma \geq 5 \mathrm{~cm}$ ) bands extend offshore southwestward from Tehuantepec and Papagayo Gaps. For convenience, the northern band will be referred to as the Tehuantepec HV band, and the southern one as the Papagayo HV band. Maximum wind variability is found along the mean wind jets in the Gulfs of Tehuantepec and Papagayo, representing the intensification and retreat of the jets. SSH HV bands are found on the northwest flank of wind HV bands, suggestive of the latter forcing the former. Over the Gulf of Panama, a region of relatively high $\mathrm{SSH}$ variance $(\sigma \sim 4 \mathrm{~cm})$ is found under the gap wind jet.

[19] To map spatiotemporal structure of subseasonal variability, we correlate SSHA with the reference time series in a $1^{\circ} \times 1^{\circ}$ box centered at the variance maximum in each HV band (Figure 4b). The result reveals the coherent structures (e.g., correlation of alternating signs) within the Tehuantepec and Papagayo bands, indicative of eddy train formation. In the Gulf of Panama, by contrast, SSHA is weak, localized and entirely of the same sign. The weak response is likely due 

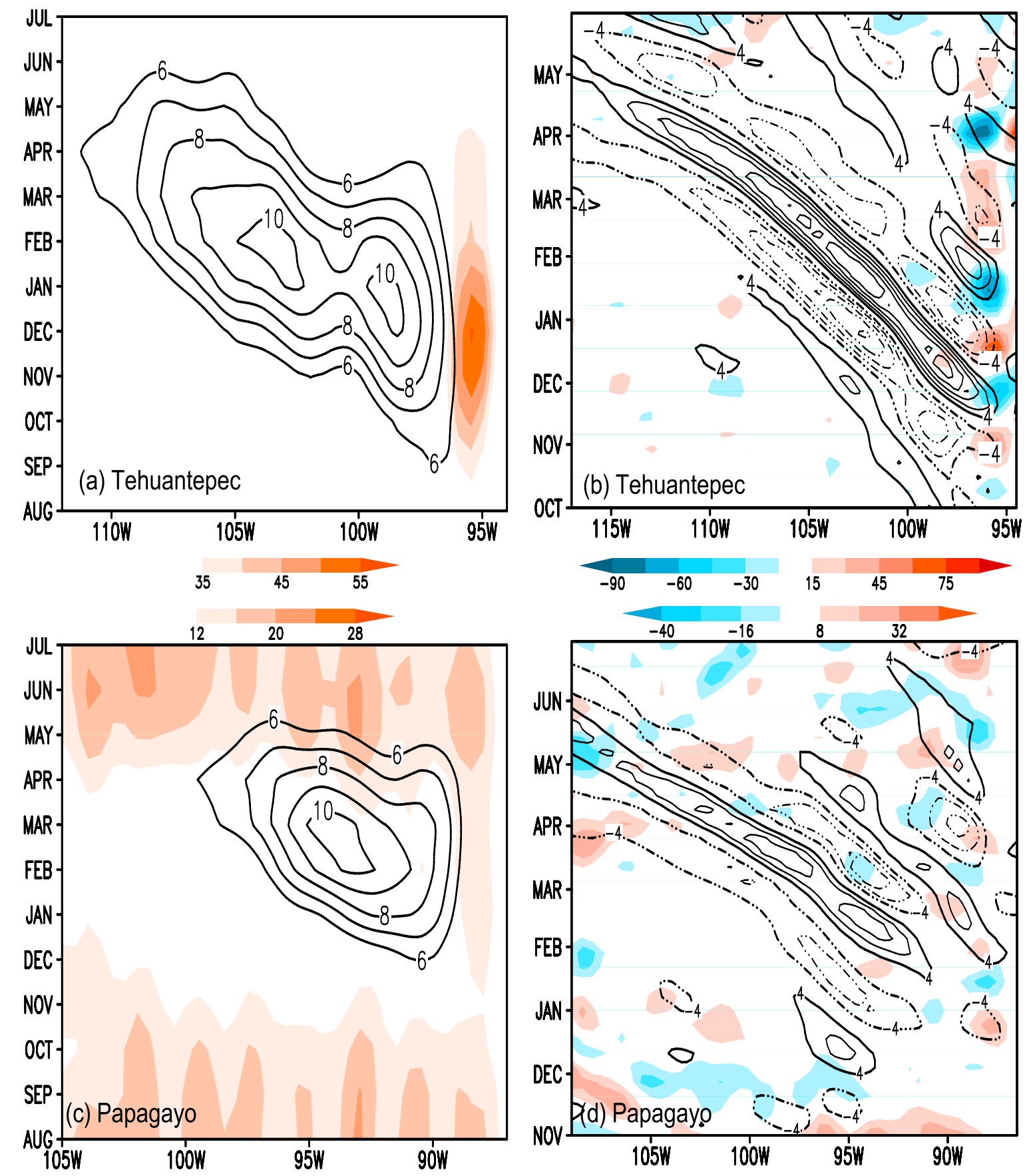

Figure 5. Time-distance diagram of climatological standard deviation of SSHA (cm; contour) and wind stress curl anomaly $\left(\times 10^{-8} \mathrm{~N} / \mathrm{m}^{3}\right.$; color) along the HV band of (a) Tehuantepec and (c) Pagagayo. Timedistance diagram of anomalous SSH (cm; contour) and wind stress curl $\left(\times 10^{-8} \mathrm{~N} / \mathrm{m}^{3}\right.$; color) for October 2002-June 2003 along the HV band of (b) Tehuantepec and (d) Papagayo. The contour interval in Figures $5 \mathrm{~b}$ and $5 \mathrm{~d}$ is $4 \mathrm{~cm}$.

to the weaker variability of the Panama wind jet (Figure 4a). From here on, we will focus on the eddy trains in the Tehuantepec and Papagayo HV bands. Throughout this paper, positive SSH anomalies and thermocline troughs are consistently referred to as anticyclonic.

\subsection{Tehuantepec}

[20] Figure 5a shows standard deviations of SSHA and wind curl along the Tehuantepec HV band (see Figure 4b), as a function of distance and calendar month. Subseasonal variability in the Tehuantepec jet starts to increase in September, peaks in December, and then gradually decays. Near the coast, SSH variance shows a seasonal cycle similar to that of wind curls, with large values for October-March. Further offshore, it displays a southwest propagation, with the peak delayed to February at $105^{\circ} \mathrm{W}$. This is consistent with the offshore propagation of individual eddies, as during the winter season of 2002-03 in Figure 5b. A strong positive 

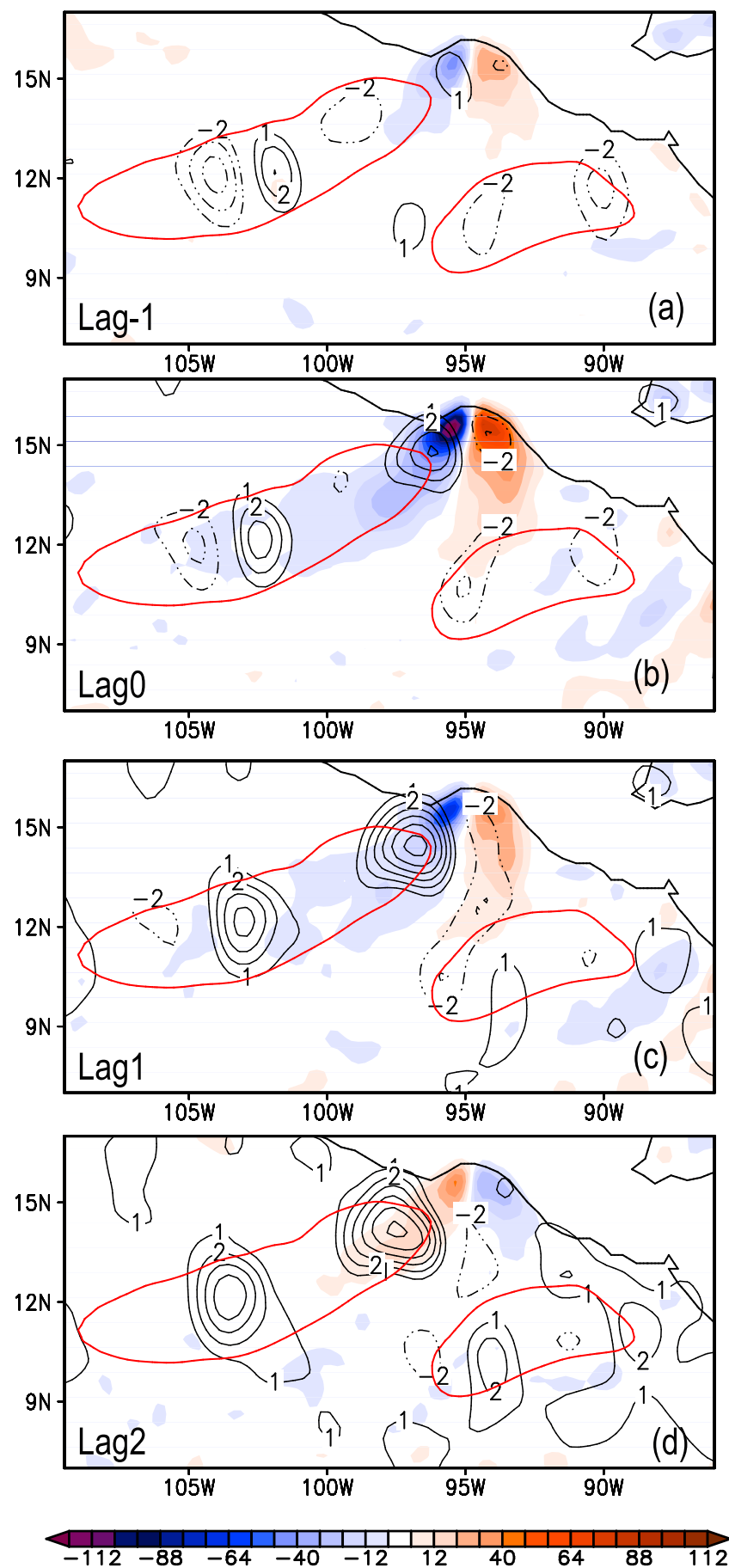

Figure 6. Tehuantepec high-wind composite. Wind stress curl anomaly $\left(\times 10^{-8} \mathrm{~N} / \mathrm{m}^{3}\right.$; color) and SSHA (cm; contour). The red contour denotes the SSHA $\sigma=6.5 \mathrm{~cm}$ (DecemberMarch), representative of high variance bands. Time lags are in weeks.

SSH anomaly develops near the coast in late November 2002 when the Tehuantepec jet intensifies with strong Ekman downwelling on its northwest flank. The SSH anomaly eventually propagates offshore, $2000 \mathrm{~km}$ away to $115^{\circ} \mathrm{W}$ six months later in May 2003. There are several other occasions during this gap wind season where positive (negative) SSH anomalies develop near the coast in response to
Ekman downwelling (upwelling), and then propagate offshore. This suggests gap wind variability as an important forcing of subseasonal SSH variability in the Tehuantepec HV band.

[21] A Tehuantepec gap wind index is defined as wind speed anomalies at $\left(95^{\circ} \mathrm{W}, 15^{\circ} \mathrm{N}\right)$, where the subseasonal wind variance is maximum during the gap wind season (see Figure 4a). We conduct a composite analysis by averaging 16 high-wind events when the wind speed anomaly in the Tehuantepec index time series exceeds $1 \sigma$ during October-June from 2000 to 2005. Figure 6 shows the results. At lag -1 week, the wind speed starts to increase, with a signature wind-curl dipole of magnitude $>10 \times 10^{-8} \mathrm{~N} / \mathrm{m}^{3}$ (Figure $6 \mathrm{a}$ ). A pair of small weak eddies forms in the dipole forcing near the coast, with the anticyclonic eddy $(\mathrm{SSHA}=+1 \mathrm{~cm})$ to the west and the cyclonic one (SSHA $=-1 \mathrm{~cm}$ ) to the east. At lag 0, the curl dipole reaches its maximum, with a band of strong downwelling curl $\left(<-15 \times 10^{-8} \mathrm{~N} / \mathrm{m}^{3}\right)$ covering the HV band. Near the coast, the eddy pair grows in magnitude, with the anticyclonic eddy bigger in size and magnitude than the cyclonic one (Figure 6b). At lag week 1, the gap wind begins to weaken, and the anticyclonic coastal eddy reaches the maximum strength $(\mathrm{SSHA}=6.2 \mathrm{~cm})$ (Figure $6 \mathrm{c})$. The Tehuantepec wind curl anomalies flip signs at lag week 2 , marking the retreat of the wind jet. The anticyclonic eddy remains strong $(\mathrm{SSHA} \sim 6 \mathrm{~cm})$ and slowly propagates offshore.

[22] Figure 7 shows the distance-time section of the composite wind curl and SSH anomalies along Tehuantepec HV

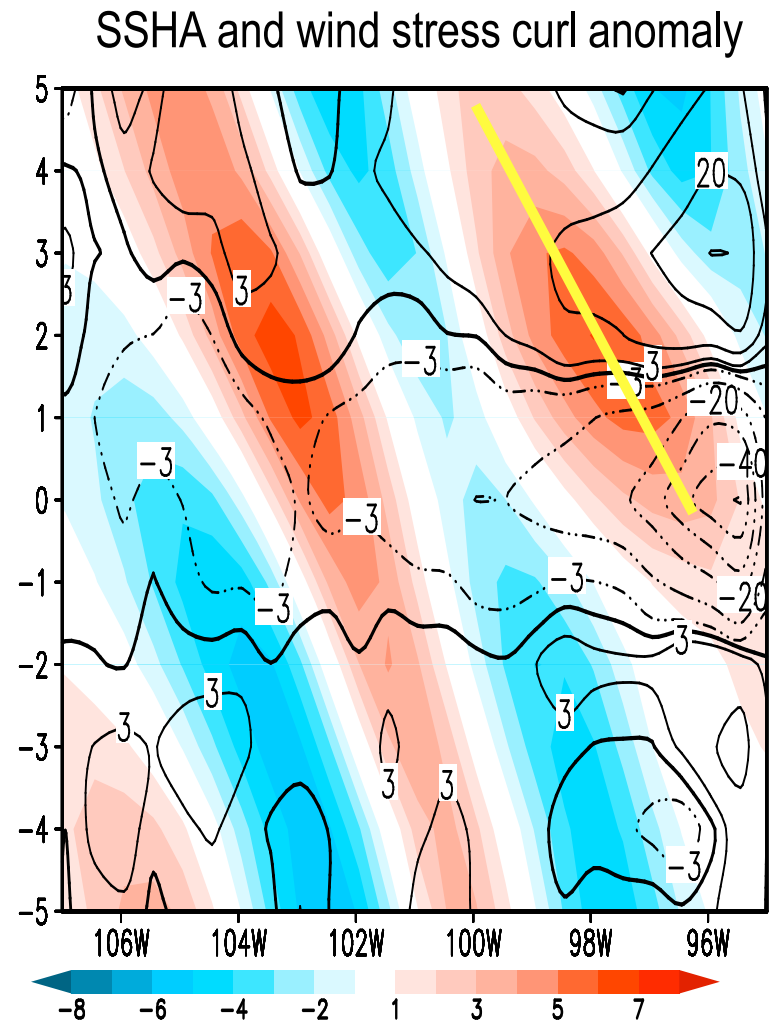

Figure 7. Distance-time diagram of SSHA (cm; color) and wind stress curl anomaly $\left(\times 10^{-8} \mathrm{~N} / \mathrm{m}^{3}\right.$; contour $)$ from Tehuantepec high-wind composite along Tehuantepec axis. The $y$ axis indicates lags (in week). The offshore propagation speed, indicated by the yellow slope, is $13 \mathrm{~cm} / \mathrm{s}$. 

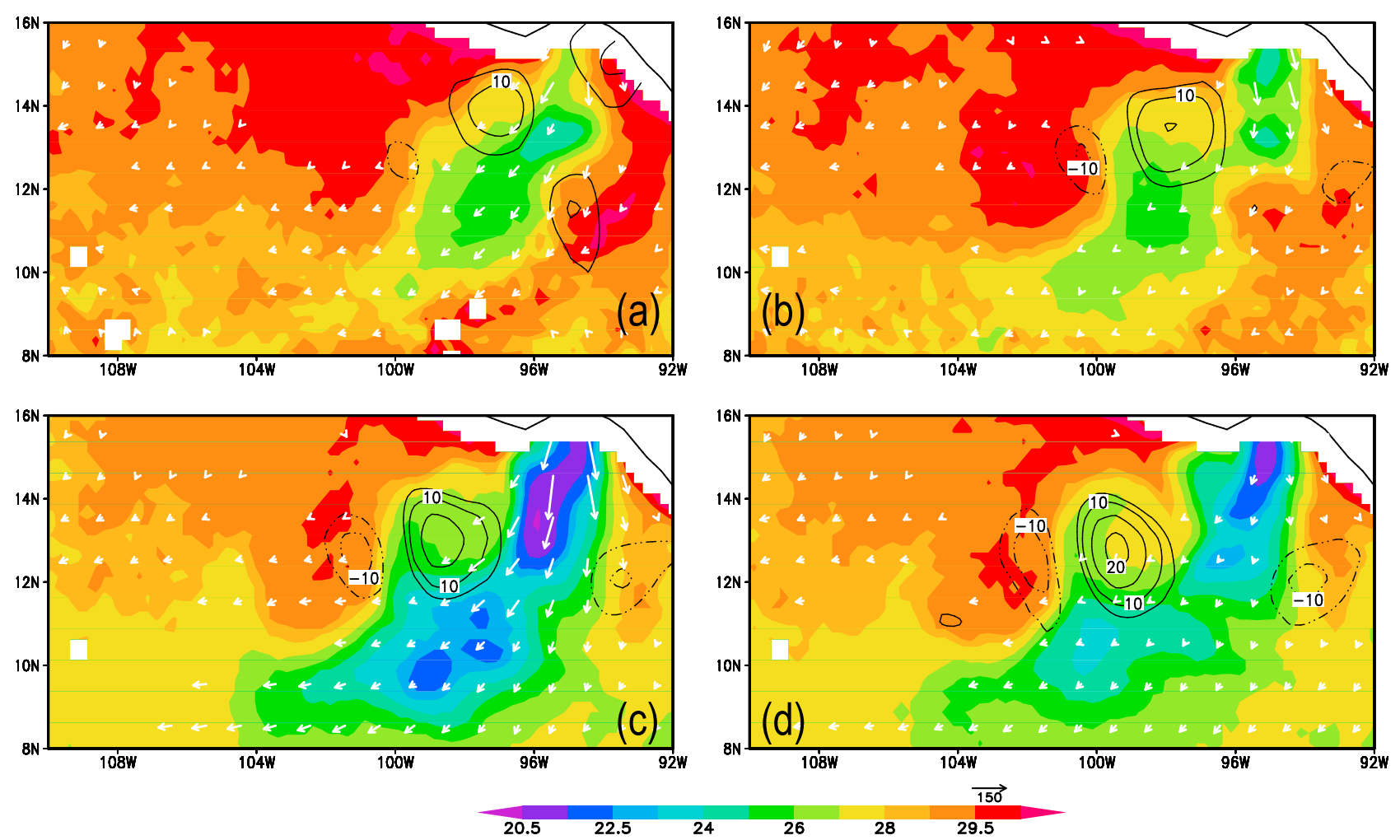

Figure 8. Development of cold SST patch and eddy formation during a gap wind event 26 November17 December 2003. SST $\left({ }^{\circ} \mathrm{C}\right.$; color), SSHA (cm; contour), and QSCAT pseudo wind stress $\left(\mathrm{m}^{2} / \mathrm{s}^{2} ;\right.$ vector) (a) 19 November, (b) 26 November, (c) 3 December, and (d) 10 December 2003. The contour interval for SSHA is $5 \mathrm{~cm}$.

band. A subseasonal gap wind event typically lasts about 3-4 weeks, which accounts for half the cycle of the SSH variability off Tehuantepec. Hence the complete cycle (6-8 weeks) falls within the 40-90 day band, consistent with our spectral analysis (Figure 3a). Its downwelling curls force positive SSH anomalies that grow eventually to 6-7 $\mathrm{cm}$ and propagates offshore. The eddy propagation speed is estimated to be about $13 \mathrm{~cm} / \mathrm{s}$, consistent with previous estimates of 11-19 cm/s [Willett et al., 2006]. The downwelling curls extends far offshore to at least $107^{\circ} \mathrm{W}$, apparently causing positive SSH anomalies to intensify and negative ones to weaken offshore in the HV band. In particular, the positive $\mathrm{SSH}$ anomalies in $104^{\circ}-102^{\circ} \mathrm{W}$, originating from the previous wind event, strengthen considerably from lag week -1 to +2 in response to the intensified wind jet. The re-intensification of this offshore anticyclonic eddy in $104^{\circ}-$ $102^{\circ} \mathrm{W}$ is captured in plan views of composite anomalies (Figure 6). Such an intensification of a slow varying eddy by a succession of wind pulses, analogous to a "whip and top," is consistent with previous findings [Barton et al., 1993]. Indeed, SSH variance shows two peaks (Figure 4a), centered at $\left(98^{\circ} \mathrm{W}, 13.5^{\circ} \mathrm{N}\right)$ and $\left(103^{\circ} \mathrm{W}, 12^{\circ} \mathrm{N}\right)$, corresponding to the nearshore growth and offshore intensification of anticyclonic SSH anomalies in Figures 6 and 7. At lags 0 and 1 in Figure 6, the downwelling wind curls seem to weaken over this offshore anticyclonic eddy, probably because the QuikSCAT scatterometer measures sea surface stress due not only to wind but to ocean current as well [Kelly et al., 2001]. The anticyclonic eddy contributes cyclonic surface stress, leading to the weakening of anticyclonic stress curls (estimated to amount to $\sim 16 \%$ ).

[23] In general, Ekman pumping velocity may be cast as

$$
w_{E}=\nabla \times \frac{\tau}{f+\zeta},
$$

where $\tau$ is the wind stress vector, $\mathrm{f}$ is the Coriolis parameter, and $\zeta$ is sea surface relative vorticity [Stern, 1965; Niiler, 1969; Thomas and Rhines, 2002; Pedlosky, 2007]. For Tehuantepec eddies, the Rossby number $(|\zeta| / f)$ is about 0.2 , resulting in moderate modification of Ekman pumping by relative vorticity. We have calculated the nonlinear Ekman pumping and found a weak enhancement $(\sim 9 \%)$ in windforcing relative to linear Ekman pumping over the offshore anticyclonic eddy centered around $\left(103^{\circ} \mathrm{W}, 12^{\circ} \mathrm{N}\right)$.

\subsection{Papagayo}

[24] Figure 5c shows the distance-time section of SSH variance along the Papagayo HV band. Subseasonal SSH variability is strong during December-May, delayed by a month behind the Tehuantepec HV band. The Papagayo and Tehuantepec jets are somewhat correlated in their subseasonal intensification (Figure 6). Indeed the Tehuantepec high-wind composite shows some indication that an anticyclonic eddy grows on the northwest flank of the Papagayo jet following the jet intensification (lag weeks 1 and 2). Overall SSH anomalies are much less well correlated with 

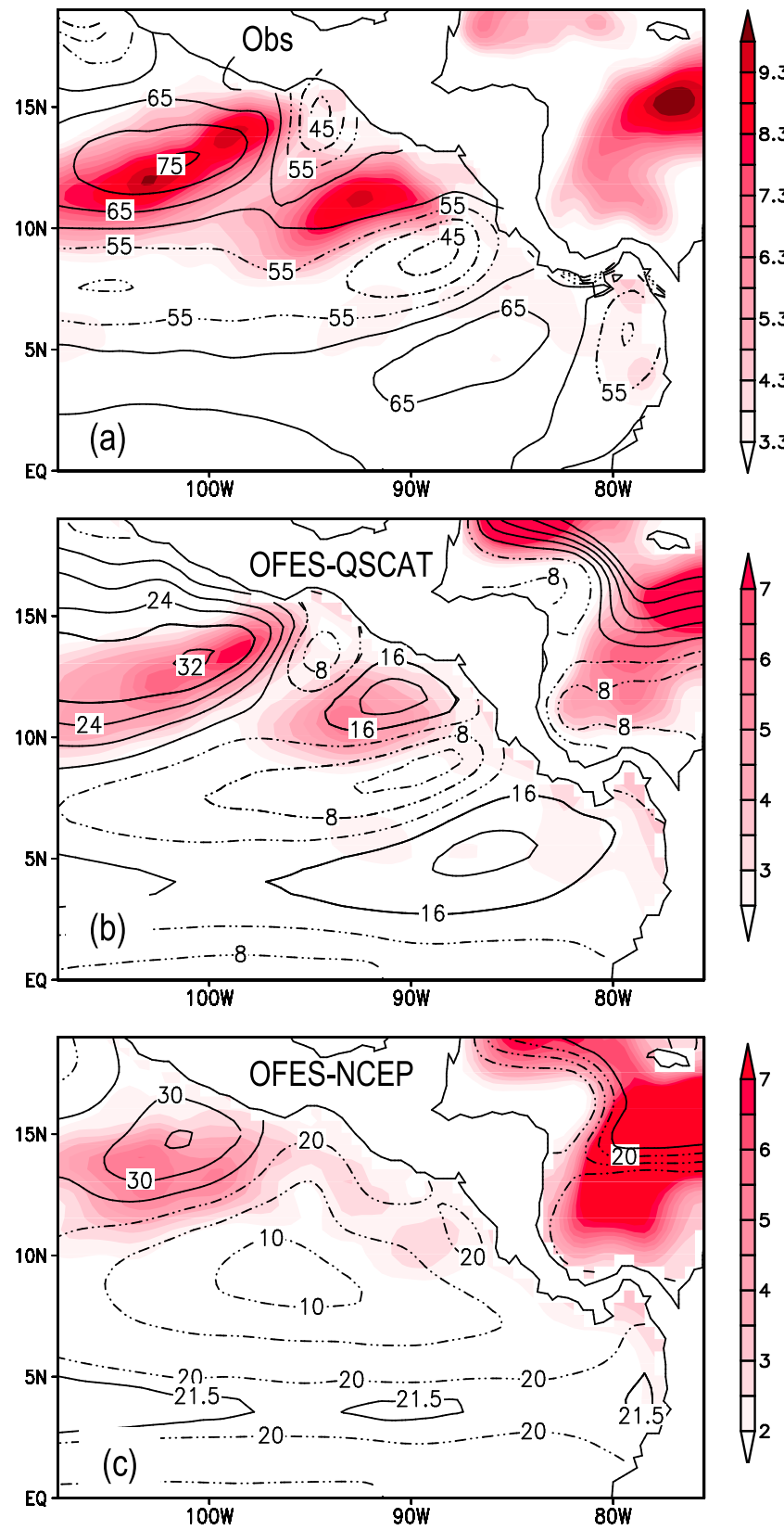

Figure 9. Standard deviation of SSHA, $\sigma$, (cm; color) and mean of SSH (cm; contour) December-March (a) observation (1993-2005), (b) OFES QSCAT run (2000-2005), and (c) OFES NCEP run (1997-2004). The contour intervals for Figures $9 \mathrm{a}, 9 \mathrm{~b}$, and $9 \mathrm{c}$ are $5 \mathrm{~cm}, 4 \mathrm{~cm}$, and $5 \mathrm{~cm}$, respectively.

the wind jet intensity in the Papagayo than in the Tehuantepec HV band (see also Figure 5d). A composite analysis based on the Papagayo jet speed results in much less coherent structure in SSH than the Tehuantepec composite [Chang, 2009]. There are several possible reasons for this difference. First, wind variability is considerably weaker in Papagayo than Tehuantepec (Figure 4a). Weak wind-forcing allows other mechanisms to play a role in Papagayo eddy formation, such as instabilities of the mean flow [Hansen and Maul, 1991] and coastal Kelvin wave [Zamudio et al.,
2006]. In summer/fall, the Gulf of Papagayo falls within the ITCZ where the subseasonal variance of convection and wind is locally enhanced as the Madden-Julian Oscillation propagates eastward from the western Pacific [Small et al., 2011]. SSH variance is small because wind curl variability associated with the MJO is of too large a horizontal scale to excite eddies. In summer/fall off Papagayo, the climatological winds are weaker, and gap wind events are infrequent.

\subsection{SST Response}

[25] The Tehuantepec wind jet leaves a cool patch in winter SST climatology by enhanced turbulent heat flux and vertical mixing [Xie et al., 2005]. Likewise, subseasonal variability in wind and SSH induces a pronounced SST response. Figure 8 shows the SST and eddy (SSHA) fields during a subseasonal gap wind event during 19 November 2003-10 December 2003. In Figure 8a, a single weak anticyclonic eddy $(\mathrm{SSHA}=10 \mathrm{~cm})$ forms upon the gap wind onset. The cold SST patch $\left(25^{\circ} \mathrm{C}-26^{\circ} \mathrm{C}\right)$ has formed, with $\Delta \mathrm{SST} \approx 4^{\circ} \mathrm{C}$ relative to the surroundings. A week later, the coastal eddy grows $(\max \mathrm{SSHA}=15 \mathrm{~cm}$ ) as it slowly propagates southwestward away from the coast (Figure 8b). In the meantime, the swirl of the eddy advects the cold water from the cold patch outward, resulting in a cusp-like structure on the northwest flank of the cold patch. Subsequently, the gap wind strengthens and so is the cold patch (min $\mathrm{SST} \leq 21^{\circ} \mathrm{C}$ ) with $\Delta \mathrm{SST} \approx 8^{\circ} \mathrm{C}$ (Figure $8 \mathrm{c}$ ). Figure $8 \mathrm{~d}$ shows the subseasonal development of the cold patch and a cusp on

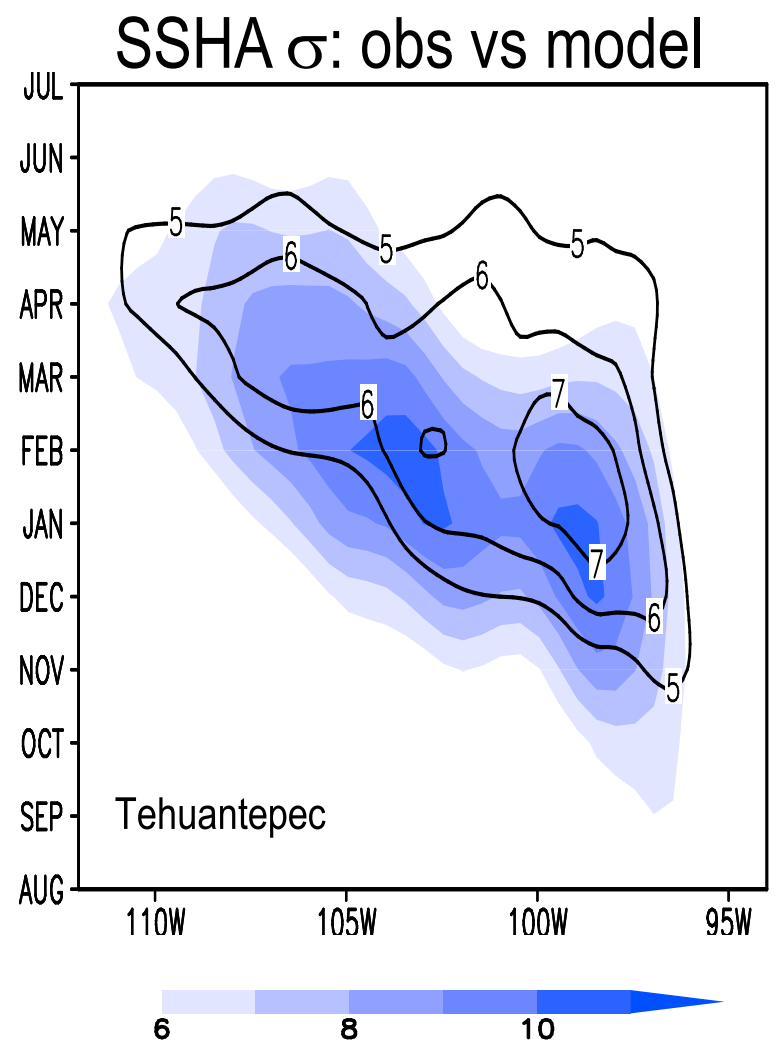

Figure 10. Distance-time diagram of climatological SSHA variability $(\sigma ; \mathrm{cm})$ Observation (color) versus OFESQSCAT run (contour) along the Tehuantepec band. 
SSHA: obs vs model

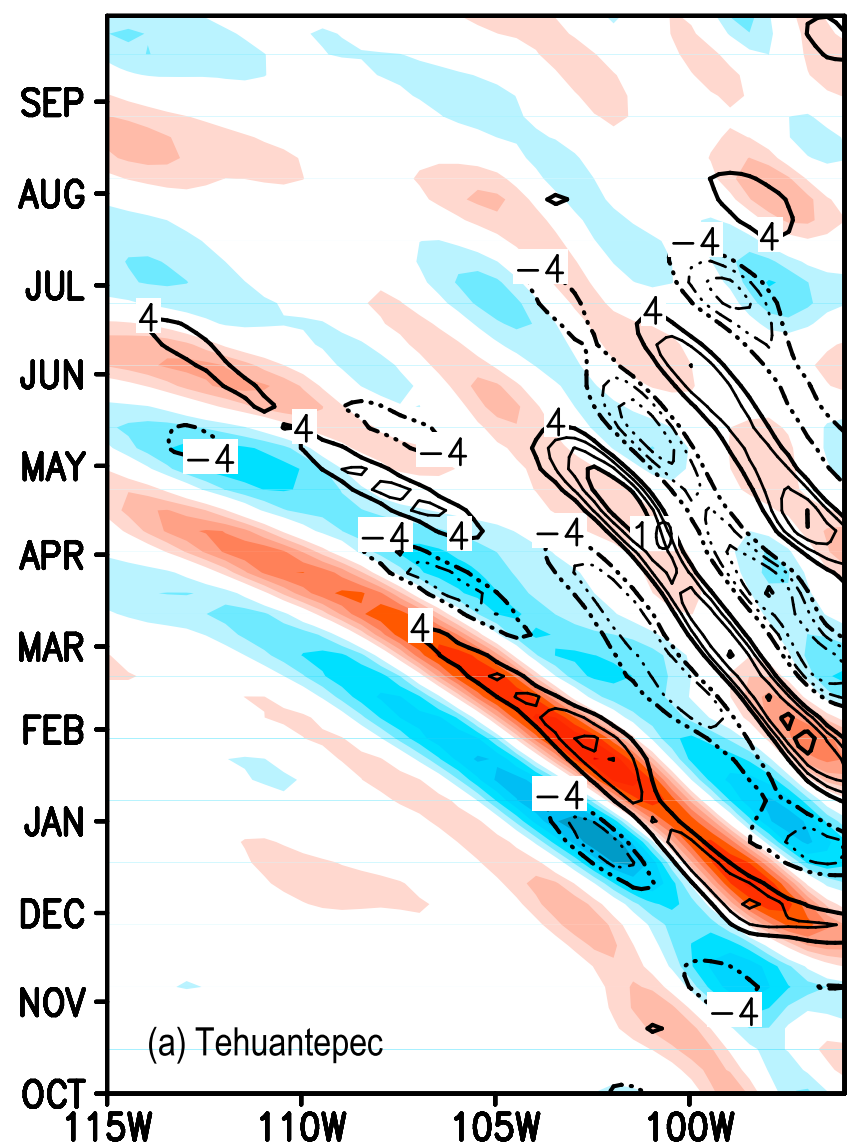

SSHA: obs vs model

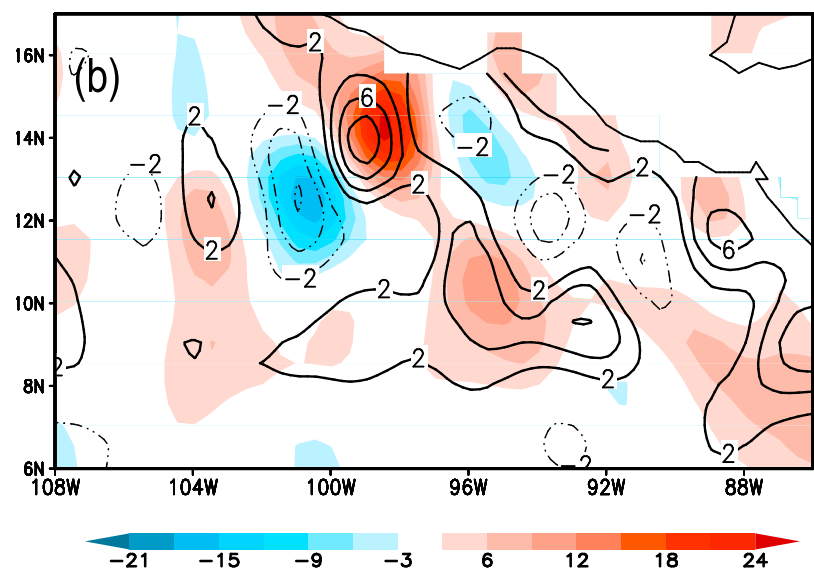

Figure 11. Comparison between observation and OFES-QSCAT run. (a) Distance-time diagram of SSHA (cm) observation (color) versus OFES-QSCAT run (contour) along Tehuantepec from October 2002 to September 2003. The contour interval is $2 \mathrm{~cm}$. (b) Eddy field in plan view (SSHA in $\mathrm{cm}$ ): observation (color) versus OFES-QSCAT run (contour) on 11 December 2002. The contour interval is $2 \mathrm{~cm}$.

its northwest flank, as the eddy continues to strengthen along its path $(\max \mathrm{SSH}>20 \mathrm{~cm})$. The cusp of the SST front is due to the advection of the cold water by the anticyclonic eddy.

\section{Model Simulation}

[26] Figure 9 compares December-March simulations in the OFES QSCAT and NCEP runs to observations. The seasonal-mean SSH field in observations is characterized by southwest-tilted banded structures (Figure 9a), including the Tehuantepec Bowl, the Tehuantepec bump, the Papagayo Trough, and the Costa Rica Dome. The bands of high subseasonal variance are found over the thermocline troughs of anticyclonic mean circulation off Tehuantepec and Papagayo. The QSCAT run reproduces the mean surface circulation including all the major troughs and ridges associated with the wind jets. The Tehuantepec and Papagayo $\mathrm{HV}$ bands are also reproduced well, collocated with the troughs in the mean surface topography. The NCEP run, however, fails to reproduce narrow banded structures in the mean SSH field except the Tehuantepec Bowl and the Costa Rica Dome. The subseasonal variance distribution also looks quite different from observations: the Tehuantepec HV band is not well developed in its southwest extension while the
Papagayo HV band is almost missing. The comparison between the QSCAT and NCEP runs and with observations indicates that high-resolution wind-forcing is critical for the realistic simulation of the mean circulation as well as subseasonal variability off Central America. In the rest of the paper, we analyze results from the QSCAT run.

[27] Figure 10 compares subseasonal variance between observations and the QSCAT run in a distance-time section along the Tehuantepec band. The model reproduces the seasonality of the variance quite well, including the increase in winter and offshore propagation. The model, however, underestimates the subseasonal variance by $30-40 \%$. With an effective resolution of $1^{\circ}$, the J-OFURO product of QuikSCAT wind used to force the model smoothes out orographic wind jets. The seasonal peak of the SSH variance is delayed by a month in the model compared to observations for reasons not immediately clear.

[28] The distance-time section in Figure 11a shows that during the gap-wind season of 2002-03, the model reproduces the phase and offshore propagation of observed SSH anomalies in the Tehuantepec HV band remarkably well, especially over the first $1000 \mathrm{~km}$ off the coast. The plan view in Figure $11 \mathrm{~b}$ confirms the model skills in simulating the 

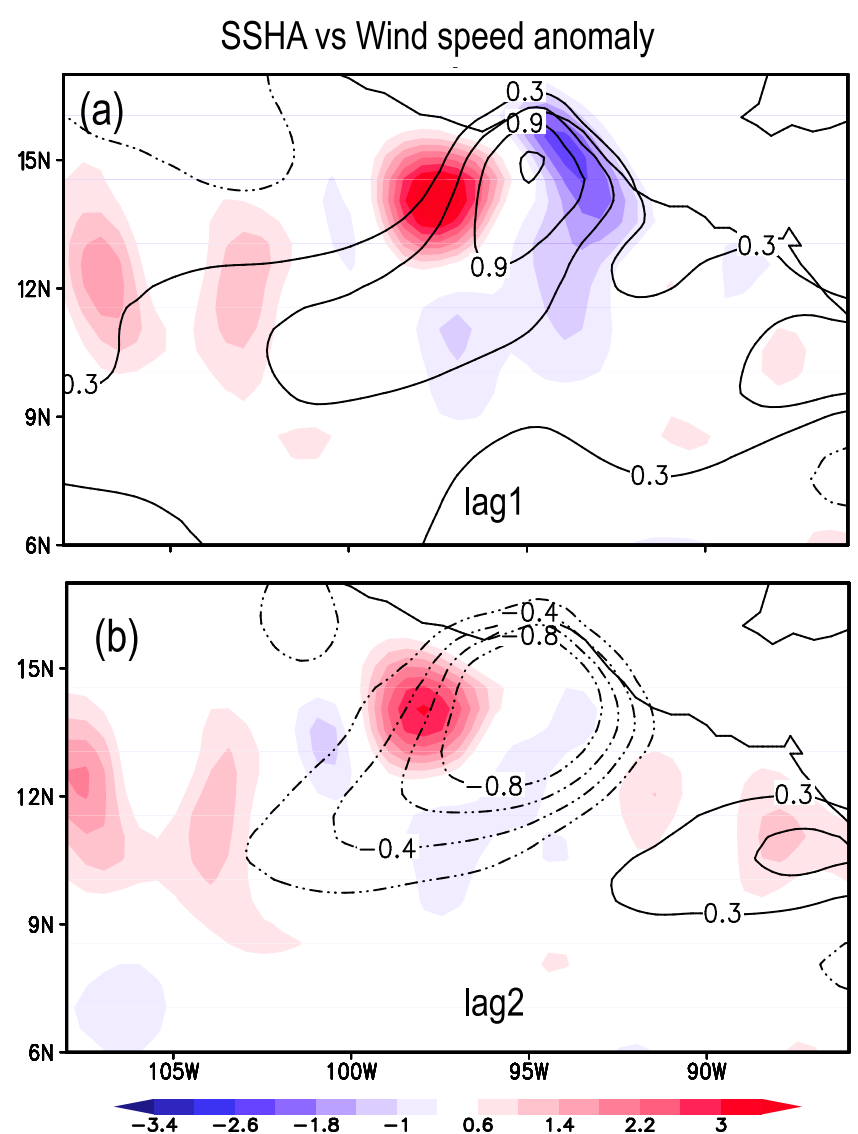

Figure 12. OFES-QSCAT run Tehuantepec high-wind composite SSHA (cm; color) and wind speed anomaly $(\mathrm{m} / \mathrm{s}$; contour) at (a) lag 1 and (b) lag 2. Lags are in weeks.

southwest-slanted eddy train. While individual eddies may be slightly displaced in phase, the correspondence between observations and the QSCAT run is obvious.

\subsection{High-Wind Composite}

[29] We carry out a composite analysis using a criterion that the northerly wind stress anomaly of the Tehuantepec jet exceeds $0.75 \sigma\left(-\tau_{\mathrm{y}}>0.75 \sigma\right)$ in the J-OFURO product for the gap wind season (see Figure 2a). A total 18 events qualified during 2000-2005. Figure 12 shows the composite anomalies of wind speed and SSH in the model. As in observations (section 3.2), the anticyclonic coastal eddy begins to grow on the northwest flank of the Tehuantepec wind jet at lag 0 , and reaches its maximum $(\mathrm{SSHA}=+3.6 \mathrm{~cm}$ ) at lag week 1 . The southwest offshore propagation is also captured in the model. As the anticyclonic eddy grows, the negative SSH anomaly on the southeast flank of the wind jet decays from lag week 1 to 2 as the wind speed decreases.

[30] Figure 13 compares the high-wind composites based on observations and the OFES simulation in a distance-time section along the Tehuantepec HV band. The agreement between observations and the simulation is striking, both in phase and offshore propagation speed $(13 \mathrm{~cm} / \mathrm{s})$. The model captures the observed response to a high-wind event: the growth of the coastal anticyclonic eddy, the re-intensification of the offshore anticyclonic eddy, and the weakening of cyclonic perturbations. Compared to observations, the simulated SSH anomalies are weaker. The root-mean square
(RMS) of the Rossby number $\left(R_{o}\right)$ for the gap wind season is $\mathrm{O}(0.1)$ for the OFES simulation, as opposed to $\mathrm{O}(0.2)$ in observations.

\subsection{Energetics Analysis}

[31] Our observation analysis and the skill of the OFES model in simulating the phase of Tehuantepec eddies indicate that wind variability is important in setting the phase of subseasonal variability in SSH. This does not rule out contributions from instabilities of mean current. The OFES simulation permits a quantitative estimate of the relative importance between wind-forcing and hydrodynamic instability.

[32] We follow Lorenz's [1955] four-box energy model to investigate the energy transfer processes [Zhuang et al., 2010]. The governing equation for total eddy energy (TEE; the sum of eddy kinetic and potential energies) can be written as

$$
\frac{\partial T E E}{\partial t}=T_{2}+T_{4}+W W E+\text { other terms. }
$$

[33] The three generation terms on the right side are baroclinic conversion from mean to eddy potential energy,

$$
T 2=-\frac{g}{\rho\left(\partial \bar{\rho}_{\theta} / \partial z\right)}\left(u^{\prime} \tilde{\rho}^{\prime} \frac{\partial \overline{\tilde{\rho}}}{\partial x}+v^{\prime} \tilde{\rho}^{\prime} \frac{\partial \overline{\tilde{\rho}}}{\partial y}\right) ;
$$

barotropic conversion,

$$
T 4=-\left(u^{\prime} u^{\prime} \frac{\partial \bar{u}}{\partial x}+u^{\prime} v^{\prime}\left(\frac{\partial \bar{v}}{\partial x}+\frac{\partial \bar{u}}{\partial y}\right)+v^{\prime} v^{\prime} \frac{\partial \bar{v}}{\partial y}\right) ;
$$

\section{SSHA: obs vs model}

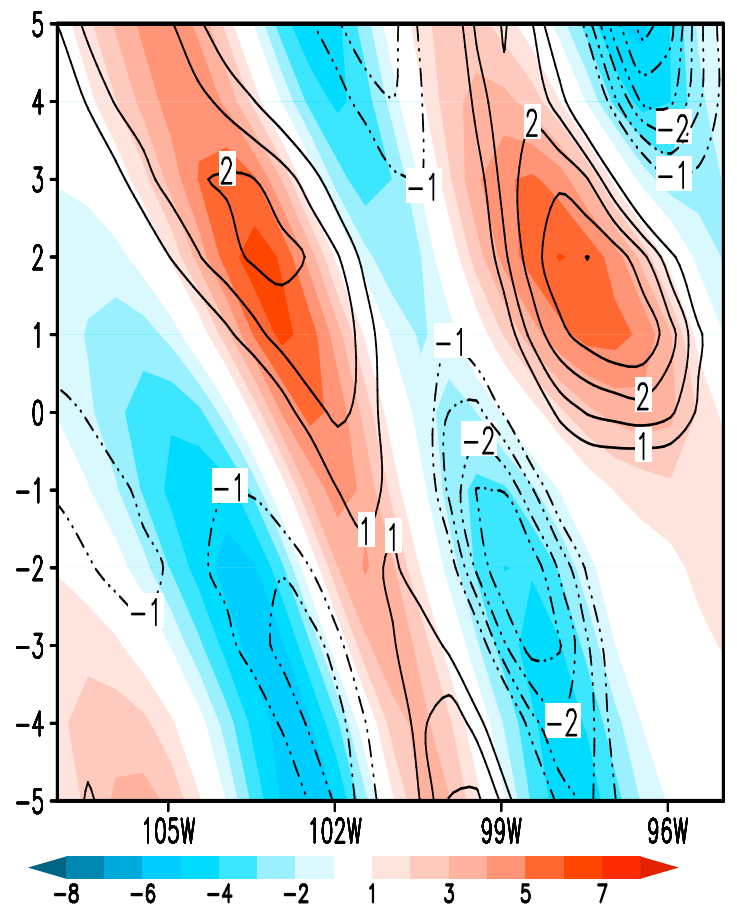

Figure 13. Distance-time diagram of composite SSHA (cm) observation (color) versus OFES-QSCAT run (contour) along Tehuantepec band. The $y$ axis indicates lags (in week). 

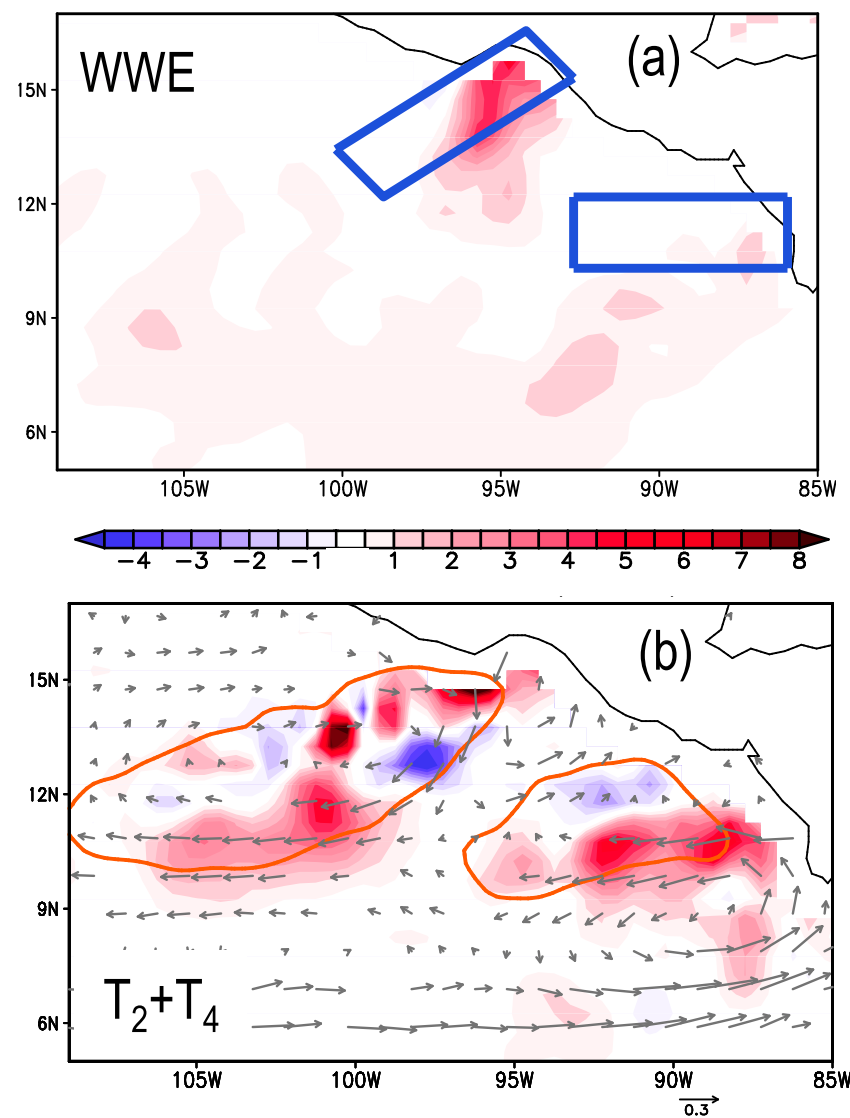

Figure 14. Energetics analysis averaged over NovemberMarch (1999-2005): (a) wind work (color; $\mathrm{cm}^{3} / \mathrm{s}^{3}$ ) and (b) sum of baroclinic $\left(\mathrm{T}_{2}\right)$ and barotropic $\left(\mathrm{T}_{4}\right)$ conversion terms (color; $\mathrm{cm}^{3} / \mathrm{s}^{3}$ ) and mean ocean current (vector; $\mathrm{m} / \mathrm{s}$ ) superimposed with the high variance bands (SSHA $\sigma=5 \mathrm{~cm}$ ) in orange contour. The energetics quantities shown here are vertically integrated. The boxes for estimation of seasonal mean values in Table 1 are indicated in Figure 14a.

and wind work done by eddy:

$$
W W E=\frac{\overline{u_{s}^{\prime} \tau_{x}+v_{s}^{\prime} \tau_{y}}}{\rho D} .
$$

[34] Here $\tilde{\rho}(x, y, z, t)=\rho(x, y, z, t)-\rho_{b}(z), \rho_{b}(z)$ is the background density profile as represented by the annual and horizontal mean, and $\bar{\rho}_{\theta}(z)$ is the annual and horizontal mean potential density. The over bar and prime denote the mean and perturbation, $(\mathrm{u}, \mathrm{v})$ are the current velocity, the subscript $s$ denotes surface values, $\left(\tau_{\mathrm{x}}, \tau_{\mathrm{y}}\right)$ are the wind stress vector, $\rho$ is water density, $\mathrm{D}$ is the mixed layer depth, and $\mathrm{g}$ is the gravity. The low-frequency ( $>120$ days) variability is treated as the mean. The vertical integrals of $T_{2}$ and $T_{4}$ are calculated by integrating over the entire water column, and their positive values indicate barotropic and baroclinic energy conversion from the mean flow to the eddies, respectively.

[35] Figure 14 shows the November-March mean values of $T_{2}+T_{4}$, and WWE. The wind work is everywhere positive. It features a strong maximum of $5 \mathrm{~cm}^{3} / \mathrm{s}^{3}$ in the region of Tehuantepec eddy genesis, consistent with our earlier result about the importance of wind-forcing. No such peak is found in the Papagayo eddy genesis region (Figure 14a). The contribution from hydrodynamic instabilities is important for both the Tehuantepec and Papagayo HV bands. In the nearcoastal region of Tehuantepec eddy genesis, the instability conversion is comparable to the wind work, whereas the instability conversion is larger than the wind work for the Papagayo HV band.

[36] Table 1 shows the seasonal-mean (November-March) values of EKE, $T_{2}, T_{4}$, and WWE averaged in boxes in Figure 14a. These boxes are chosen to capture high EKE off Tehuantepec and Papagayo, respectively. The high EKE band $\left(4 \times 10^{6} \mathrm{~cm}^{3} / \mathrm{s}^{2}\right)$ is located within the core of high variance bands (not shown). The wind work term is large for the Tehuantepec box, with comparable contribution from the barotropic conversion and somewhat less from the baroclinic conversion term. For the Papagayo box, the baroclinic conversion term dominates, and contribution from the wind work is small, consistent with our result that eddies there are not well correlated with wind variability.

\section{Discussion}

[37] This section discusses several properties of Tehuantepec eddies and investigates the origin of subseasonal wind variability off Central America.

\subsection{Asymmetry About the Wind Jet Axis}

[38] Subseasonal SSH variability is preferentially generated on the northwest flank of the Tehuantepec and Papagayo jets (Figure 4a). This is partially due to the fact that the wind jets are not symmetric but feature stronger curls on the northwest than the southeast flank. The wind curl variance shows strong asymmetry about the Tehuantepec wind jet axis (Figure 15). The maximum in curl standard deviation is $60 \times 10^{-8}$ and $35 \times 10^{-8} \mathrm{~N} / \mathrm{m}^{3}$ on the northwest and southeast flanks of the Tehuantepec jet, respectively. In addition, the Tehuantepec jet is strongly curved in an anticyclonic sense [Clarke, 1988], producing stronger anticyclonic curls on the northwest than cyclonic curls on the southeast flank of an intensified wind jet.

[39] In the ocean, nonlinear Ekman pumping (section 3.1) makes a moderate contribution to the asymmetry as the development of the anticyclonic ocean eddy reduces the absolute vorticity ( $f+\zeta$ ) on the northwest flank. The mean ocean circulation is also likely to be a factor in shaping SSH variability. Both the Tehuantepec and Papagayo HV bands are collocated with a thermocline trough. This, coupled with the fact that an intensified wind jet excites preferentially anticyclonic eddies, reduces entrainment damping. On the southeast flank of the wind jet, the mean and anomalous upwelling enhance damping on thermocline perturbations [McCreary

Table 1. Seasonal and Area Averaged Values of Eddy Kinetic Energy (EKE), Wind Work (WWE), Baroclinic ( $\left.\mathrm{T}_{2}\right)$, and Barotropic $\left(\mathrm{T}_{4}\right)$ Conversion Terms From November to March, 2000-2005

\begin{tabular}{lcc}
\hline & Tehuantepec & Papagayo \\
\hline EKE $\left(10^{6} \mathrm{~cm}^{3} / \mathrm{s}^{2}\right)$ & 4.65 & 4.13 \\
$\mathrm{WWE}\left(\mathrm{cm}^{3} / \mathrm{s}^{3}\right)$ & 1.31 & 0.45 \\
$\mathrm{~T}_{2}\left(\mathrm{~cm}^{3} / \mathrm{s}^{3}\right)$ & 0.54 & 1.64 \\
$\mathrm{~T}_{4}\left(\mathrm{~cm}^{3} / \mathrm{s}^{3}\right)$ & 1.03 & 0.73 \\
\hline
\end{tabular}




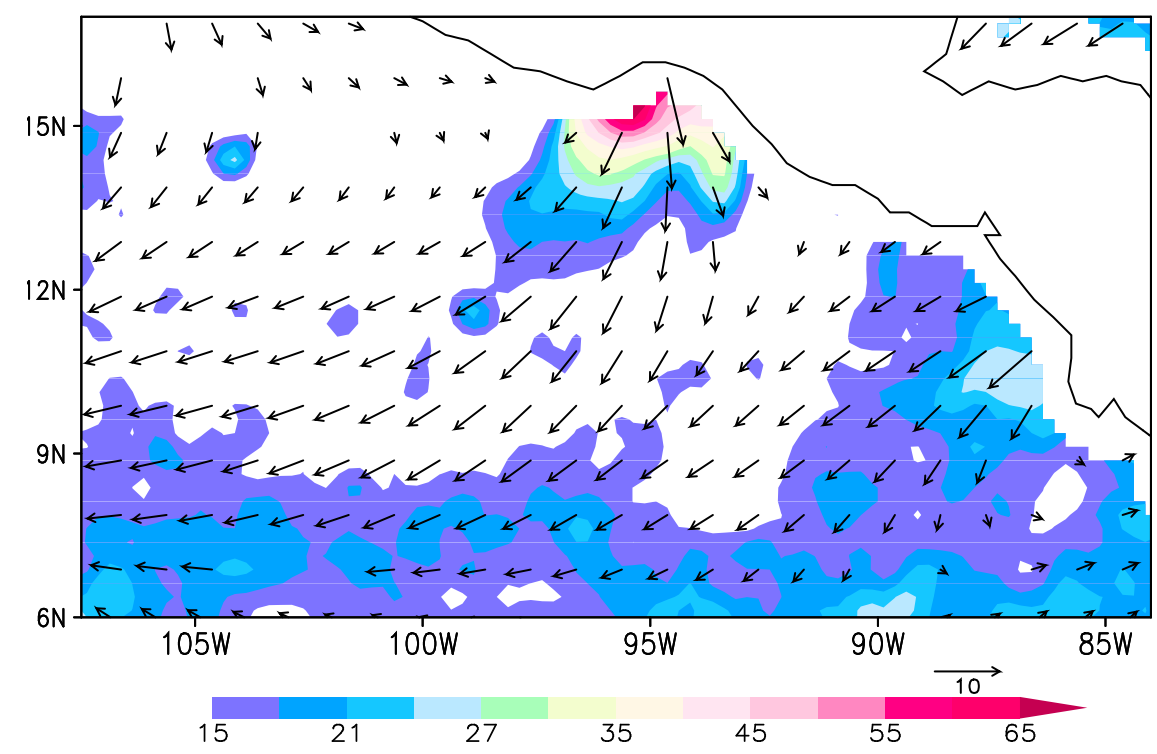

Figure 15. The standard deviation of wind stress curl $\left(\times 10^{-8} \mathrm{~N} / \mathrm{m}^{3}\right.$; color $)$ superimposed on the mean wind stress vectors $(\mathrm{m} / \mathrm{s}$; vector) for the winter season (December-March).

et al., 1989]. Thermocline troughs off Tehuantepec and Papagayo feature horizontal and vertical current shears, sources of barotropic and baroclinic instabilities that energize eddies as revealed in the energetics analysis (section 4.2).

\subsection{Southwest Propagation}

[40] Off Tehuantepec and Papagayo, subseasonal eddies are of length scales much larger than the Rossby radius of deformation and hence in near-geostrophic balance. In this regime, both the baroclinic Rossby waves and nonlinear eddies propagate/translate following the linear Rossby wave dispersion relation [McWilliams and Flierl, 1979; Farrar and Weller, 2006]. We use the graphic approach [LonguetHiggins, 1964; Pedlosky, 2003] to examine if the observed phase propagation is consistent with the Rossby wave dispersion relation.

[41] The Rossby wave dispersion relation may be cast as

$$
\left(k+\frac{\beta}{2 \omega}\right)^{2}+l^{2}=\frac{\beta^{2}}{4 \omega^{2}}-\frac{1}{L_{d}^{2}},
$$

where $(k, l)$ are zonal and meridional wave numbers, $L_{d}$ is the Rossby radius of deformation, $\beta=\frac{d f}{d y}$, the latitudinal variation of the Coriolis parameter, and $\omega$ is the frequency. Equation (5) represents a circle, $C_{2}$, on the $k$ - $l$ plane with the center at $\left(-\frac{\beta}{2 \omega}, 0\right)$ and radius of $\sqrt{\frac{\beta^{2}}{4 \omega^{2}}-\frac{1}{L_{d}{ }^{2}}}$. For a given latitude, $C_{2}$ is a function of $\omega$ and $L_{d}$.

[42] The phase vectors of the subseasonal eddy propagation within the HV bands of Tehuantepec and Papagayo are shown in Figure 16a in green arrows. We also estimate the wavelength in the direction of eddy propagation: $\mathrm{L}=660 \mathrm{~km}$ and $590 \mathrm{~km}$ for Tehuantepec and Papagayo eddies, respectively. In Figure $16 \mathrm{~b}$ and Figure $16 \mathrm{c}, C_{1}$ represents the circle with radius of the observed total wave number, $\left|\frac{2 \pi}{L}\right|$, for Tehuantepec and Papagayo, respectively. The intersection points between $C_{1}$ and $C_{2}$ give Rossby wave solutions. With the estimates of $\mathrm{L}$ and $\mathrm{L}_{\mathrm{d}}$ in Table 2 , on the $k$ - $l$ plane, we vary $C_{2}$ with $\omega$ changing from $\frac{2 \pi}{120}$ to $\frac{2 \pi}{20}$ day $^{-1}$ until $\mathrm{C}_{1}$ and $\mathrm{C}_{2}$ circles intersect exactly at the observed phase vector. The corresponding periods, 85 days and 50 days for Tehuantepec and Papagayo, respectively, are in agreement with observations (see Figure 3).

[43] Eddies off Tehuantepec and Papagayo are not simply neutral Rossby waves. Given that hydrodynamic instabilities are important in eddy energetics, the mean flow probably plays an important role in steering eddies. For instance, the thermocline troughs off Tehuantepec and Papagayo are oriented in a southwest direction (Figure 9a). While the linear Rossby wave dispersion relation permits both the southwest and northwest propagation, the northwest-southeast tilted eddies (Figure 16a) are leaning against the background flow to extract energy from it [Pedlosky, 1987], resulting in the southwest slanted HV bands.

[44] On the other hand, the southwestward current along the southeast flank of the Tehuantepec Bowl, as depicted in Figure 16a, is likely to be the mean expression of the passage of eddies. Compared with the Tehuantepec Bowl of the linear Rossby wave model (Figure 10) [Kessler, 2006], the observed mean gyre (Figure 9a) is smoother, especially near the HV band. The smoother feature in the observations is likely due to eddy mixing that is not represented in the linear Rossby model [Kessler, 2006]. The Tehuantepec Bowl is 10-20 cm deep in SSH compared to the environment while eddies are of an amplitude of $10 \mathrm{~cm}$ in standard deviation (Figure 9a). The large amplitudes of Tehuantepec eddies point to the need of nonlinear analysis.

\subsection{Atmospheric Variability}

[45] This section examines the connection of the regional gap wind with the large-scale atmospheric circulation. The Madden-Julian Oscillation (MJO) is the dominant mode of variability in the tropical atmosphere on the intraseasonal 

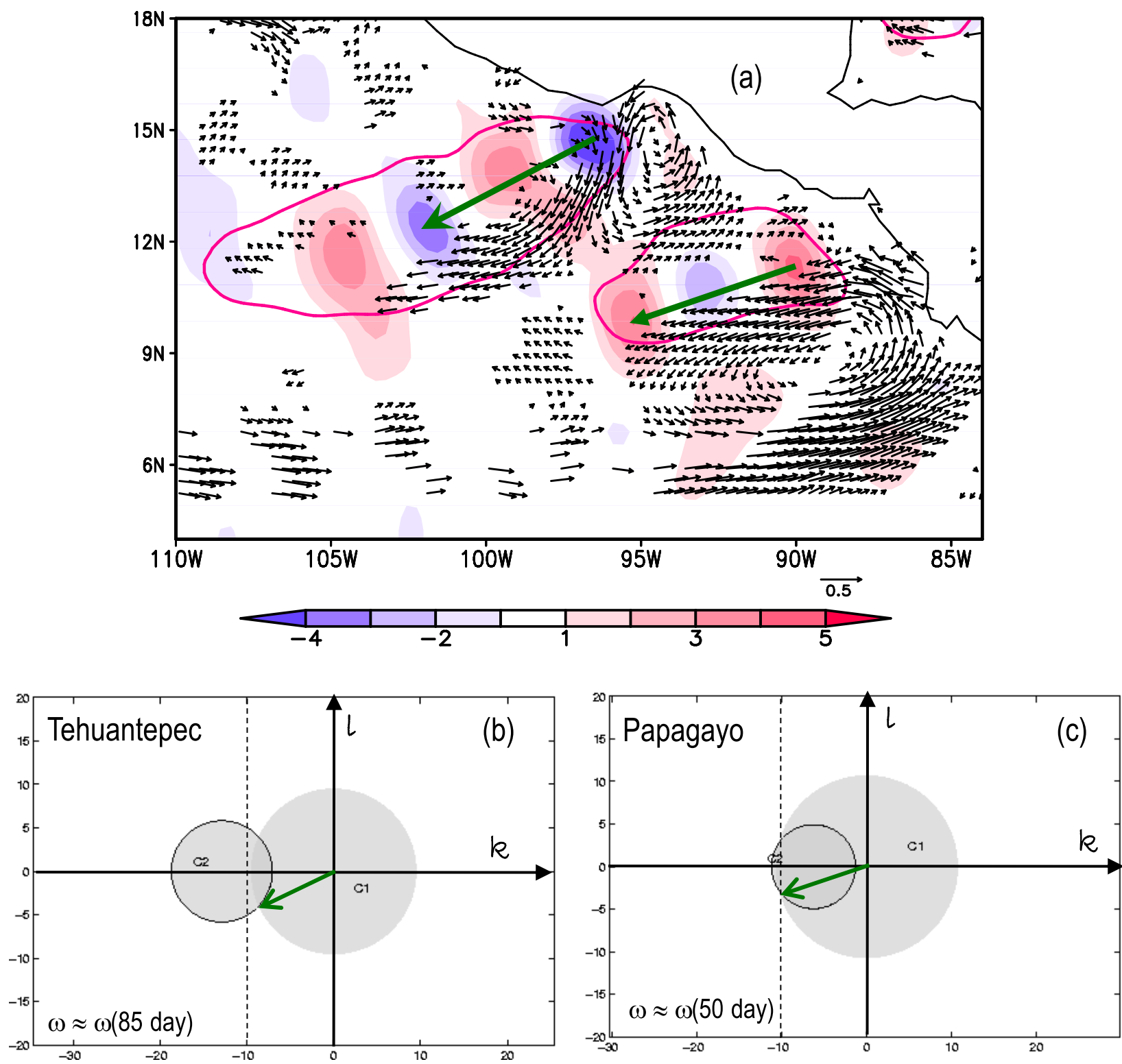

Figure 16. (a) Southwest propagation: mean ocean circulation (vector; $\mathrm{m} / \mathrm{s}$ ) and SSHA (color; $\mathrm{cm}$ ) from the Tehuantepec high-wind composite at lag +4 . Green arrows indicate the phase vectors. The high variance bands (SSHA $\sigma=5.5 \mathrm{~cm}$ ) are marked in pink contours. Graphical approach shows that the observed phase vector (green arrow), wave numbers $\left(k, l\right.$ in $\left.10^{-6} \mathrm{~m}^{-1}\right)$ and frequency $\left(\omega\right.$ in $\left.d a y^{-1}\right)$ satisfy the local Rossby dispersion relation for (b) Tehuantepec and (c) Papagayo.

timescale [Zhang, 2005]. To obtain the large-scale atmospheric circulation pattern associated with the $\mathrm{MJO}$, we regressed $950 \mathrm{hPa}$ geopotential height and precipitation onto the MJO index of Maloney and Hartmann [1998] based on empirical orthogonal function analysis of $850 \mathrm{hPa}$ wind. Figure $17 \mathrm{a}$ shows the regressed map over the tropical Pacific for November-February at lag 1 , a week after the MJO index peaks. Convective heating is located in the western Pacific with easterly winds east of the international dateline. In the pressure field, the negative geopotential height seems associated with the warm tropospheric Kelvin wave in response to the enhanced convection over western Pacific
(Figure 17a). Figure 17b shows the correlation coefficient (r) of subseasonal surface wind with respect to the MJO index over the eastern tropical Pacific (Figure 17b) at lag week 1. We see that the Papagayo jet is significantly correlated with

Table 2. Parameters for the Rossby Dispersion Calculation ${ }^{\mathrm{a}}$

\begin{tabular}{lcc}
\hline & Tehuantepec & Papagayo \\
\hline$L(\mathrm{~km})$ & 660 & 590 \\
$L_{d}(\mathrm{~km})$ & 87 & 143 \\
$2 \pi / \omega($ day) & 85 & 50 \\
\hline
\end{tabular}

${ }^{\mathrm{a}} L$ is the wavelength, $L_{d}$ is the estimated Rossby radius of deformation, and $2 \pi / \omega$ the wave period. 

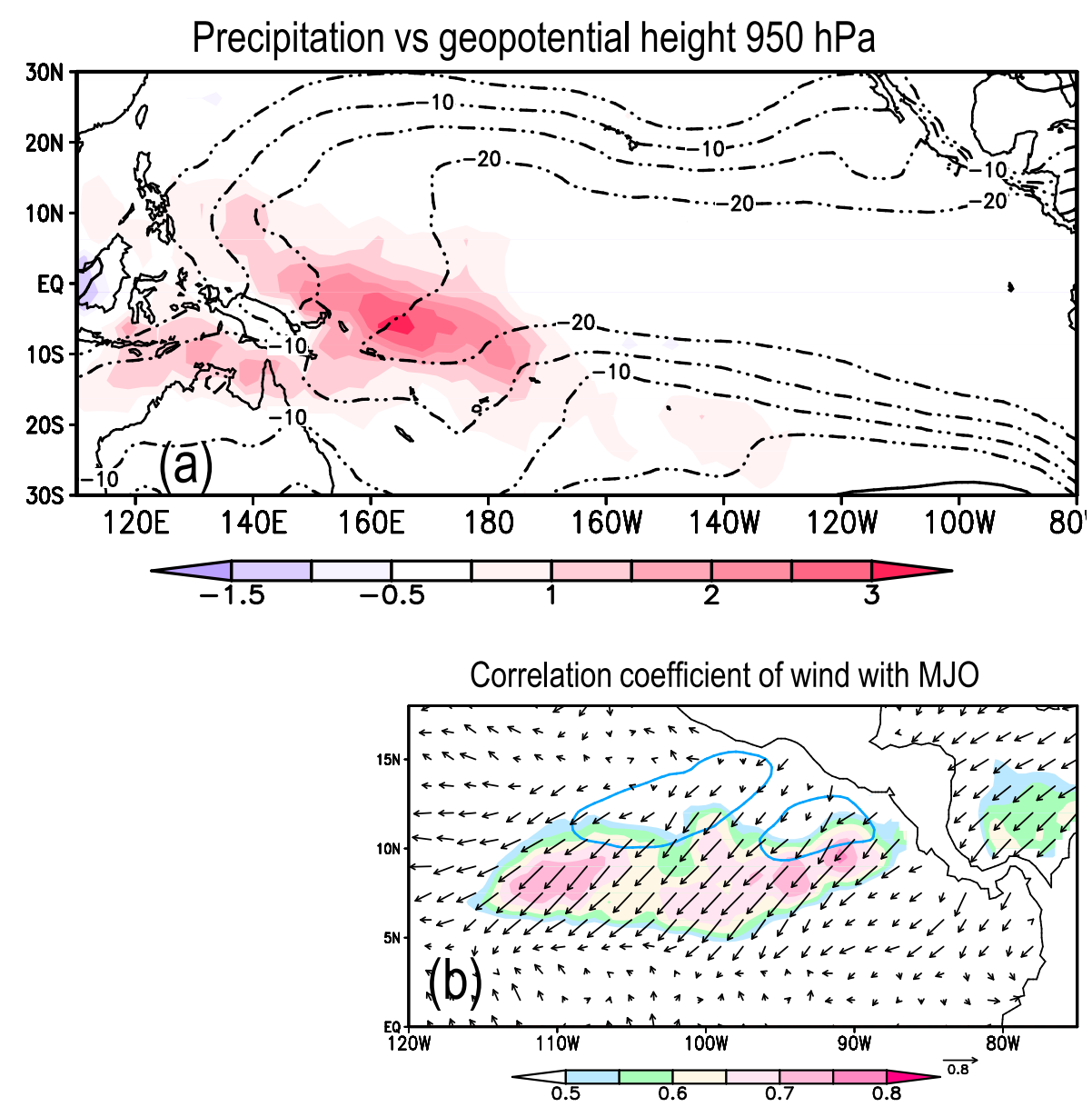

Figure 17. (a) MJO-regressed Climate Prediction Center merged analysis of precipitation (CMAP) rain pattern (mm; color) and the ERA-40 950-hPa geopotential height (m; contour) over the tropical Pacific at lag 1 week. (b) Correlation coefficient, $\mathrm{r}$, of anomalous wind $\left(\tau_{x}, \tau_{y}\right)$ (vector) with the global MJO index at $\mathrm{t}=$ lag 1 (week) for the gap wind season (Nov-Feb) during the period 2000-2004. The areas of $\mathrm{r}>0.5$ are shaded in colors. With a period of 35 days, we estimate the degree of freedom for five gap wind seasons to be 15 , and the correlation is $95 \%$ significant at 0.48 based on student-t test. The blue contour lines in Figure $17 \mathrm{~b}$ indicate the HV bands (SSHA $\sigma=5 \mathrm{~cm}$ ).

the MJO index, with $\mathrm{r} \sim 0.65$ far exceeding $95 \%$ significance level. The Tehuantepec jet correlation with MJO, however, is marginal at $r \sim 0.2$. Figure 18 shows lag regression of surface wind upon the MJO index. At lag 0, wind anomalies begin to emerge in the far East Pacific, accelerating the northeasterly trades and gap winds. The northeasterly wind anomalies are strongest at lag week 1 .

[46] In contrast to the Papagayo jet, Tehuantepec wind variability is due to perturbations from the midlatitudes. The lag correlation of ERA $1000 \mathrm{hPa}$ geopotential height with the Tehuantepec gap wind index for November-February shows that the intensified Tehuantepec jet is associated with a high pressure system that is centered on the east flank of the Sierra Madre and covers almost the entire United States (Figure 19). The strong pressure gradient across the Sierra Madre drives an intense wind jet over the Gulf of Tehuantepec, consistent with previous studies of synoptic intensification of the wind jet [Steenburgh et al., 1998; Chelton et al., 2000a, 2000b]. On subseasonal timescales, this high-pressure system begins to emerge with significant correlation a week prior to the gap wind onset, and decays rapidly one week after the onset [Chang, 2009].

\section{Summary}

[47] We have investigated how orographic wind jets force ocean subseasonal variability in the East Pacific warm pool. The blockage of large-scale northeasterly winds by Central American Cordillera results in intense wind jets on the lee side at mountain gaps. The wind stress curls associated with the wind jets drive ocean currents and excite propagating SSH signals. For a wind jet like that off Tehuantepec with a significant zonal component, the variability in its intensity spins up and sheds eddies. For a weak wind jet like that off Panama, its weak variability induces only localized SSH response along the jet axis.

[48] Early studies of ocean eddy formation off Tehuantepec and Papagayo observed surface wind and SSH/ thermocline depth only infrequently from ships. They are now routinely monitored from space with a broad spatial coverage at weekly or better temporal resolution. We take 

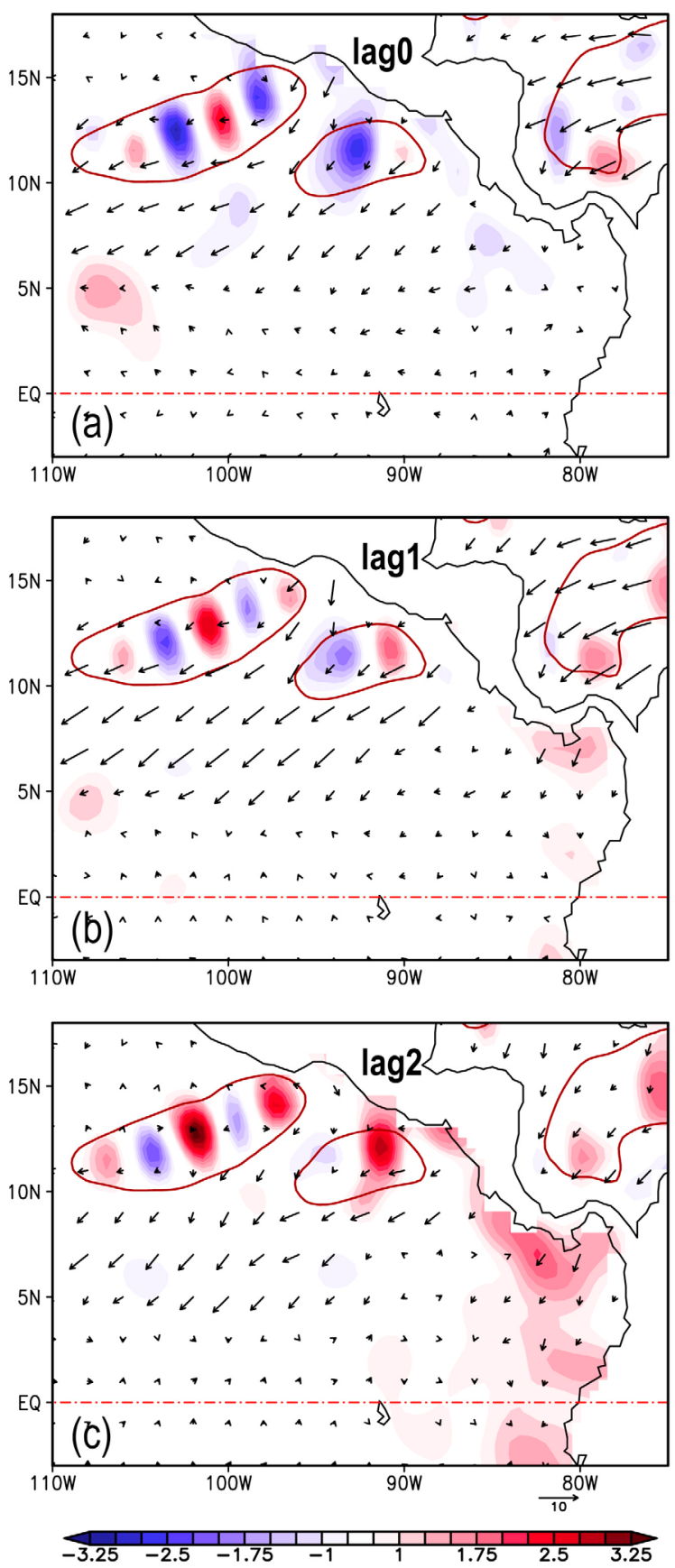

Figure 18. Lag regression analysis with the global MJO for the gap wind season (Nov-Feb) during the period 2000 2004: anomalous pseudo wind stress $\left(\tau_{x}, \tau_{y}\right)\left(\mathrm{m}^{2} / \mathrm{s}^{2}\right.$; vector $)$ and SSHA (cm; color). Lags are in weeks.

advantage of the enhanced spatiotemporal sampling capability from space and show that the independent measurements of wind and SSH are mutually consistent in the framework of wind-forced ocean adjustments on subseasonal timescales.

[49] As demonstrated in Kessler [2002], the regional mean circulation can be reasonably well diagnosed based on linear Sverdrup dynamics. In this study, we focus on prolonged sequence of synoptic gap wind events, whose amplitude modulates on subseasonal timescales and yields long lasting
SSH signals. High-frequency gap winds force pronounced subseasonal variability in SSH that is organized into eddy trains in high SSH variance bands stretching southwestward from the mountain gaps of Tehuantepec and Papagayo. Off Tehuantepec, subseasonal eddies are initially forced by Ekman pumping near the coast but their subsequent growth along the paths is aided by dynamical instability of the mean flow. The evolution of the Tehuantepec eddy (at recurring intervals of 40-90 days) in response to a typical gap wind event is as follows. An anticyclonic eddy (diameter $\sim 300 \mathrm{~km}$ ) forms on the northwest flank of the intensified wind jet and grows in the following 2-3 weeks while propagating offshore southwestward at speed of $13 \mathrm{~cm} / \mathrm{s}$. There is evidence that this anticyclonic eddy re-intensifies downstream of the wind jet in response to the next gap wind event, as in a "whip and top" mechanism, that is, a slow varying eddy spun up by repeated wind pulses [Barton et al., 1993]. The phase propagation of ocean eddies is one order of magnitude slower than that of atmospheric easterly waves in the ITCZ [Serra and Houze, 2002].

[50] When forced with daily wind observations by the QuikSCAT satellite, an eddy-resolving OGCM reproduces the important characteristics of subseasonal SSH variability with striking similarities to observations, including the Tehuantepec and Papagayo high variance bands, and southwest phase propagation of subseasonal eddies. The simulated SSH variability is weaker in amplitude by $30-40 \%$ than observations, most likely because the time-space smoothing in the wind product reduces the intensity of narrow wind jets. The simulated phase of eddy shedding events is in good agreement with observation off Tehuantepec but not off Papagayo. Based on the model simulation, the energetics analysis reveals that dynamical instability due to mean current shear is an important mechanism for energizing the subseasonal variability along the two high variance bands. Our energetics analysis shows that within the Tehuantepec band, the sum of baroclinic and barotropic conversion is

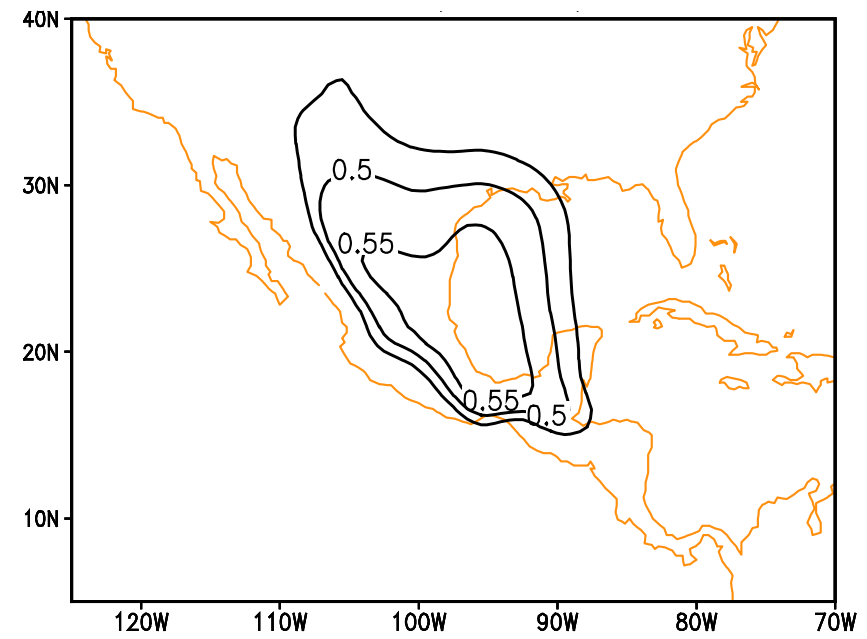

Figure 19. Simultaneous correlation of ERA-40 $1000 \mathrm{hPa}$ geopotential height with the Tehuantepec gap wind (November-February 2000-2005). The correlation is 95\% significant at 0.44 based on student-t test. The contour interval is 0.5 . 
comparable to the wind work term, whereas the former is five times larger than the latter within the Papagayo band.

[51] Tehuantepec and Papagayo eddies are often viewed as similar in the literature, but our results reveal important differences in their generation. While the former are forced by subseasonal intensification of the Tehuantepec wind jet, wind variability is much weaker (Figure 15) and poorly correlated with ocean eddy formation off Papagayo. The Papagayo wind jet is nevertheless important for ocean eddy formation, rather indirectly by driving mean current structures such as the Costa Rica Dome [Kessler 2002, 2006] whose instabilities then fuel the eddy growth (Figure 14b). Off Papagayo where wind fluctuations are weak and nearly symmetric about the wind jet axis, the high-variance band is still found on the northwest flank of the wind.

[52] Many eddies generated in the Gulfs of Tehuantepec and Papagayo continue their journey westward into the interior ocean along the high variance band near $10^{\circ} \mathrm{N}$ [Farrar and Weller, 2006]. There these eddies induce SST variability by advection of mean meridional temperature gradients that are strong during boreal spring when the ITCZ moves southward close to the equator. Co-propagation of SST and wind anomalies is commonly observed in regions of strong SST gradients [e.g., Small et al., 2005]. In the East Pacific warm pool west of $100^{\circ} \mathrm{W}$, the modulation of atmospheric convection by mesoscale SST variability has been observed along $10^{\circ} \mathrm{N}$, with more clouds found over warmer waters [Farrar, 2007].

[53] Along with earlier studies of subseasonal variability in other regions [Xie et al., 2007; Zhuang et al., 2010; Yoshida et al., 2010], our results show that wind jet fluctuations are an important mechanism for exciting subseasonal variability in SSH and the thermocline depth off Tehuantepec. The Central American gap winds leave important imprints on interannual anomalies of SST and the thermocline depth associated with El Nino/Southern Oscillation (ENSO) [Alexander et al., 2012]. ENSO also affects the gap winds, the number and intensity of ocean eddies formed in the gap wind regions [Palacios and Bograd, 2005; Zamudio et al., 2006]. Highresolution forcing fields including mesoscale wind patterns in the lee of high-topography features must be used for ocean circulation models to simulate the full range of variability on subseasonal to interannual timescales.

[54] Furthermore, the East Pacific warm pool is a region characterized by variability across a wide range of spatial and temporal scales. Clarifying the rich three-dimensional structure and processes associated with the Central American eddies revealed by the in-situ observation [Barton et al., 2009] is necessary to better understand the remaining questions such as the asymmetric behavior between cyclonic and anticyclonic eddies. In future studies, efforts that combine the in-situ as well as satellite measurements and high resolution OGCM forced with realistic wind field will serve this purpose.

[55] Acknowledgments. We wish to thank J. McCreary, R. Furue, A. Natarov, Y. Sasaki, H. Seo, T. Sampe, N. Johnson, and Cedric Chavanne for fruitful discussion, and J. Hafner for maintaining the local satellite archive. We also thank the three anonymous reviewers and Eric Barton for constructive comments that greatly improved this manuscript. We acknowledge the following data sources: Remote Sensing Systems and sponsored by the NASA Ocean Vector Winds Science Team for providing the QSCAT data (http://www.remss.com); the Collecte, Localization, Satellites (CLS) Space Oceanography Division as part of the Environment and
Climate EU ENACT project (EVK2-CT2001-00117) and with support from CNES for providing the AVISO altimeter data (available at AVISO site); Asia-Pacific Data Research Center of the IPRC for providing the Niller and Maximenko SSH climatology 1992-2002 (http://apdrc.soest.hawaii. edu/datadoc/mdot.php); the Remote Sensing Systems for providing TRMM TMI SST (http://www.ssmi.com/tmi/tmi_description.html); ECMWF data server for providing the ERA-40 reanalysis data (http://data-portal.ecmwf. int/); NOAA/OAR/ESRL PSD, Boulder, Colorado for providing CMAP Precipitation data (http://www.esrl.noaa.gov/psd/); and Japan Agency for Marine-Earth Science and Technology for providing OFES data (http:// www.jamstec.go.jp/esc/ofes/eng/). This work is supported by NASA, NSF, NOAA, JAMSTEC, the Qianren and Changjiang Projects. IPRC/ SOEST publication 910/8738.

\section{References}

Alexander, M. A., H. Seo, S.-P. Xie, and J. D. Scott (2012), ENSO's impact on the gap wind regions of the eastern tropical Pacific Ocean, J. Clim., 25, 3549-3565, doi:10.1175/JCLI-D-11-00320.1

Barton, E. D., M. L. Argote, J. Brown, P. M. Kosro, M. F. Lavín, J. M. Robles, R. M. Smith, A. Trasvinã, and H. S. Velez (1993), Supersquirt: Dynamics of the Gulf of Tehuantepec, Mexico, Oceanography, 6, 23-30.

Barton, E. D., M. F. Lavín, and A. Trasvinã (2009), Coastal circulation and hydrography in the Gulf of Tehuantepec, Mexico, during winter, Cont. Shelf Res., 29, 485-500, doi:10.1016/j.csr.2008.12.003.

Chang, C.-H. (2009), Subseasonal variability induced by orographic wind jets in the East Pacific warm pool and South China Sea, PhD thesis, 154 pp., Sch. of Earth Sci. and Technol., Univ. of Hawai'i at Mānoa, Honolulu.

Chelton, D. B., R. A. deSzoeke, M. G. Schlax, K. El Naggar, and N. Siwertz (1998), Geographical variability of the first-baroclinic Rossby radius of deformation, J. Phys. Oceanogr., 28, 433-460, doi:10.1175/ 1520-0485(1998)028<0433:GVOTFB $>2.0 . \mathrm{CO} ; 2$.

Chelton, D. B., M. H. Freilich, and S. K. Esbensen (2000a), Satellite observations of the wind jets off the Pacific coast of Central America. Part I: Case studies and statistical characteristics, Mon. Weather Rev., 128, 1993-2018, doi:10.1175/1520-0493(2000)128<1993:SOOTWJ >2.0.CO;2.

Chelton, D. B., M. H. Freilich, and S. K. Esbensen (2000b), Satellite observations of the wind jets off the Pacific coast of Central America. Part II: Regional relationships and dynamical considerations, Mon. Weather Rev., 128, 2019-2043, doi:10.1175/1520-0493(2000)128<2019:SOOTWJ $>2.0$. $\mathrm{CO} ; 2$.

Clarke, A. J. (1988), Inertial wind path and sea surface temperature patterns near the Gulf of Tehuantepec and Gulf of Papagayo, J. Geophys. Res., 93(C12), 15,491-15,501, doi:10.1029/JC093iC12p15491.

Colle, B. A., and C. F. Mass (1995), The structure and evolution of cold surges east of the Rocky Mountains, Mon. Weather Rev., 123, 2577-2610, doi:10.1175/1520-0493(1995)123<2577:TSAEOC >2.0.CO;2.

Crépon, M., and C. Richez (1982), Transient upwelling generated by twodimensional atmospheric forcing and variability in the coastline, J. Phys. Oceanogr., 12, 1437-1457, doi:10.1175/1520-0485(1982)012<1437: TUGBTD $>2.0 . C O ; 2$.

Ducet, N., P. Y. Le Traon, and G. Reverdin (2000), Global high-resolution mapping of ocean circulation from TOPEX/Poseidon and ERS-1 and-2, J. Geophys. Res, 105(C8), 19,477-19,498, doi:10.1029/2000JC900063.

Farrar, J. T. (2007), Air-sea interaction at contrasting sites in the eastern tropical Pacific: Mesoscale variability and atmospheric convection at $10^{\circ} \mathrm{N}, \mathrm{PhD}$ thesis, $166 \mathrm{pp}$., Mass. Inst. of Technol., Cambridge.

Farrar, J. T., and R. A. Weller (2006), Intraseasonal variability near $10^{\circ} \mathrm{N}$ in the eastern tropical Pacific Ocean, J. Geophys. Res., 111, C05015, doi:10.1029/2005JC002989.

Giese, B. S., J. A. Carton, and L. J. Holl (1994), Sea level variability in the eastern tropical Pacific as observed by TOPEX and the Tropical OceanGlobal Atmosphere Tropical Atmosphere-ocean Experiment, J. Geophys. Res., 99, 24,739-24,748, doi:10.1029/94JC01814.

Gonzalez-Silvera, A., E. Santamaria-del-Angel, R. Millán-Nuñez, and H. Manzo-Monroy (2004), Satellite observations of mesoscale eddies in the Gulfs of Tehuantepec and Papagayo (eastern tropical Pacific), Deep Sea Res., Part II, 51, 587-600, doi:10.1016/j.dsr2.2004.05.019.

Hansen, D. V., and G. A. Maul (1991), Anticyclonic current rings in the eastern tropical Pacific Ocean, J. Geophys. Res., 96, 6965-6979, doi:10.1029/91JC00096.

Kelly, K. A., S. Dickinson, M. J. McPhaden, and G. Johnson (2001), Currents evident in satellite wind data, Geophys. Res. Lett., 28(12), 2469-2472, doi:10.1029/2000GL012610.

Kessler, W. S. (2002), Mean three-dimensional circulation in the northeast tropical Pacific, J. Phys. Oceanogr., 32, 2457-2471, doi:10.1175/15200485-32.9.2457 
Kessler, W. S. (2006), The circulation of the eastern tropical Pacific: A review, Prog. Oceanogr., 69, 181-217, doi:10.1016/j.pocean.2006.03.009.

Kubota, M., N. Iwasaka, S. Kizu, M. Konda, and K. Kutsuwada (2002), Japanese ocean flux data sets with use of remote sensing observations (J-OFURO), J. Oceanogr., 58, 213-225, doi:10.1023/A:1015845321836.

Lee, H. S. (1990), The coastal ocean response to strong offshore winds in the gulfs of Tehuantepec and Papagayo, PhD thesis, 177 pp., Oceanogr. Cent., Nova Southeast. Univ., Fort Lauderdale, Fla.

Liang, J.-H., J. C. McWilliams, and N. Gruber (2009), High-frequency response of the ocean to mountain gap winds in the northeastern tropical Pacific, J. Geophys. Res., 114, C12005, doi:10.1029/2009JC005370.

Longuet-Higgins, M. S. (1964), On group velocity and energy flux in planetary wave motions, Deep Sea Res., 11, 35-42.

Lorenz, E. N. (1955), Available potential energy and the maintenance of the general circulation, Tellus, 7, 157-167, doi:10.1111/j.2153-3490.1955. tb01148.x

Magaña, V., J. A. Amador, and S. Medina (1999), The midsummer drought over Mexico and Central America, J. Clim., 12, 1577-1588, doi:10.1175 1520-0442(1999)012<1577:TMDOMA>2.0.CO;2.

Maloney, E. D., and D. L. Hartmann (1998), Frictional moisture convergence in a composite life cycle of the Madden-Julian oscillation, J. Clim., 11, 2387-2403, doi:10.1175/1520-0442(1998)011<2387:FMCIAC $>2.0$. $\mathrm{CO} ; 2$.

Masumoto, Y., et al. (2004), A fifty-year eddy-resolving simulation of the world ocean: Preliminary outcomes of OFES (OGCM for the Earth Simulator), J. Earth Simulator, 1, 35-56.

Maximenko, N., P. Niiler, M.-H. Rio, O. Melnichenko, L. Centurioni, D. Chambers, V. Zlotnicki, and B. Galperin (2009), Mean dynamic topography of the ocean derived from satellite and drifting buoy data using three different techniques, J. Atmos. Oceanic Technol., 26, 1910-1919, doi:10.1175/2009JTECHO672.1.

McCreary, J. P., H. S. Lee, and D. B. Enfield (1989), The response of the coastal ocean to strong offshore winds: With application to circulations in the Gulfs of Tehuantepec and Papagayo, J. Mar. Res., 47, 81-109, doi: $10.1357 / 002224089785076343$.

McWilliams, J. C., and G. R. Flierl (1979), On the evolution of isolated, nonlinear vortices, J. Phys. Oceanogr., 9, 1155-1182, doi:10.1175/ 1520-0485(1979)009<1155:OTEOIN $>2.0 . \mathrm{CO} ; 2$.

Müller-Karger, F. E., and C. Fuentes-Yaco (2000), Characteristics of windgenerated rings in the eastern tropical Pacific Ocean, J. Geophys. Res., 105, 1271-1284, doi:10.1029/1999JC900257.

Niiler, P. (1969), On the Ekman divergence in an oceanic jet, J. Geophys Res., 74, 7048-7052, doi:10.1029/JC074i028p07048.

Niiler, P. P., N. A. Maximenko, and J. C. McWilliams (2003), Dynamically balanced absolute sea level of the global ocean derived from near-surface velocity observations, Geophys. Res. Lett., 30(22), 2164, doi:10.1029/ 2003GL018628.

Palacios, D. M., and S. J. Bograd (2005), A census of Tehuantepec and Papagayo eddies in the northeastern tropical Pacific, Geophys. Res. Lett., 32, L23606, doi:10.1029/2005GL024324.

Pedlosky, J. (1987), Geophysical Fluid Dynamics, 710 pp., Springer, New York, doi:10.1007/978-1-4612-4650-3.

Pedlosky, J. (2003), Waves in the Ocean and Atmosphere, 260 pp., Springer, New York.

Pedlosky, J. (2007), A Note on Weakly Nonlinear Ekman Layer: Thickness and Flux, Woods Hole Oceanogr. Inst., Woods Hole, Mass.

Perigaud, C. (1990), Geographical variability of the first-baroclinic Rossby radius of deformation, J. Geophys. Res., 95, 7239-7248.

Reding, P. J. (1992), The Central American cold surge: An observationa analysis of the deep southward penetration of North American cold fronts, MS thesis, 177 pp., Dep. of Meteorol., Tex. A\&M Univ., College Station.

Roden, G. I. (1961), On the wind-driven circulation in the Gulf of Tehuantepec and its effect upon surface temperatures, Geofis. Int., 1, 55-76.

Romero-Centeno, R., J. Zavala-Hidalgo, A. Gallegos, and J. J. O'Brien (2003), Isthmus of Tehuantepec wind climatology and ENSO signal, J. Clim., 16, 2628-2639, doi:10.1175/1520-0442(2003)016<2628 IOTWCA $>2.0 . \mathrm{CO} ; 2$.

Romero-Centeno, R., J. Zavala-Hidalgo, and G. B. Raga (2007), Midsummer gap winds and low-level circulation over the eastern tropical Pacific, J. Clim., 20, 3768-3784, doi:10.1175/JCLI4220.1.

Sasai, Y., H. Sasaki, A. Ishida, and Y. Yamagata (2007), Marine ecosystem simulation in the eastern tropical Pacific with a global eddy resolving coupled physical-biological model, Geophys. Res. Lett., 34, L23601, doi:10.1029/2007GL031507.

Sasaki, H., and M. Nonaka (2006), Far-reaching Hawaiian Lee Countercurrent driven by wind-stress curl induced by warm SST band along the current, Geophys. Res. Lett., 33, L13602, doi:10.1029/2006GL026540.
Sasaki, H., Y. Sasai, M. Nonaka, Y. Masumoto, and S. Kawahara (2006), An eddy-resolving simulation of the quasi-global ocean driven by satellite-observed wind field: Preliminary outcomes from physical and biological fields, J. Earth Simulator, 6, 35-49.

Sasaki, H., M. Nonaka, Y. Masumoto, Y. Sasai, H. Uehara, and H. Sakuma (2008), An eddy-resolving hindcast simulation of the quasi-global ocean from 1950 to 2003 on the Earth Simulator, in High-Resolution Numerical Modeling of the Atmosphere and Ocean, chap. 10, pp. 157-186, Springer, New York.

Sasaki, H., S.-P. Xie, B. Taguchi, M. Nonaka, and Y. Masumoto (2010), Seasonal variations of the Hawaiian Lee Countercurrent induced by the meridional migration of the trade winds, Ocean Dyn., 60, 705-715, doi:10.1007/s10236-009-0258-6.

Schultz, D. M., W. E. Bracken, L. F. Bosart, G. J. Hakim, M. A. Bedrick, M. J. Dickinson, and K. R. Tyle (1997a), The 1993 superstorm cold surge: Frontal structure, gap flow, and tropical impact, Mon. Weather Rev., 125, 5-39.

Schultz, D. M., W. E. Bracken, L. F. Bosart, G. J. Hakim, M. A. Bedrick, M. J. Dickinson, and K. R. Tyle (1997b), The 1993 superstorm cold surge: Frontal structure, gap flow, and tropical impact, corrigendum, Mon. Weather Rev., 125, 662 .

Schultz, D. M., W. E. Bracken, and L. F. Bosart (1998), Planetary- and synoptic-scale signatures associated with Central American cold surges, Mon. Weather Rev., 126, 5-27, doi:10.1175/1520-0493(1998) $126<0005$ :PASSSA $>2.0 . \mathrm{CO} ; 2$.

Serra, Y. L., and R. A. Houze Jr. (2002), Observations of variability on synoptic time scales in the East Pacific ITCZ, J. Atmos. Sci., 59, 1723-1743, doi:10.1175/1520-0469(2002)059<1723:OOVOST $>2.0$. CO;2.

Small, R. J., S. P. Xie, and J. Hafner (2005), Satellite observations of mesoscale ocean features and copropagating atmospheric surface fields in the tropical belt, J. Geophys. Res., 110, C02021, doi:10.1029/ 2004JC002598.

Small, R. J. O., S. P. de Szoeke, and S.-P. Xie (2007), The Central American midsummer drought: Regional aspects and large-scale forcing, J. Clim. 20, 4853-4873, doi:10.1175/JCLI4261.1.

Small, R. J., S.-P. Xie, E. Maloney, S. P. deSzoeke, and T. Miyama (2011), Intraseasonal variability in the far-east Pacific: Investigation of the role of air-sea coupling in a regional coupled model, Clim. Dyn., 36, 867-890, doi:10.1007/s00382-010-0786-2.

Steenburgh, W. J., D. M. Schultz, and B. Colle (1998), The structure and evolution of gap outflow over the Gulf of Tehuantepec, Mexico, Mon. Weather Rev., 126, 2673-2691, doi:10.1175/1520-0493(1998) $126<2673$ :TSAEOG $>2.0 . \mathrm{CO} ; 2$

Stumpf, H. G., and R. V. Legeckis (1977), Satellite observations of mesoscale eddy dynamics in the eastern tropical Pacific Ocean, J. Phys. Oceanogr., 7 648-658, doi:10.1175/1520-0485(1977)007<0648:SOOMED $>2.0 . C O \cdot 2$.

Stern, M. E. (1965), Interaction of a uniform wind stress with a geostrophic vortex, Deep Sea Res., 12, 355-367.

Thomas, L. N., and P. B. Rhines (2002), Nonlinear stratified spin-up, J. Fluid Mech., 473, 211-244, doi:10.1017/S0022112002002367.

Trasviña, A., and E. D. Barton (2008), Summer circulation in the Mexican tropical Pacific, Deep Sea Res., Part I, 55, 587-607, doi:10.1016/ j.dsr.2008.02.002

Trasviña, A., E. D. Barton, J. Brown, H. S. Velez, P. M. Kosro, and R. L. Smith (1995), Offshore wind forcing in the Gulf of Tehuantepec, Mexico The asymmetric circulation, J. Geophys. Res., 100, 20,649-20,663, doi:10.1029/95JC01283.

Trasviña, A., E. D. Barton, H. S. Velez, and J. Brown (2003), Frontal subduction of a cool surface water mass in the Gulf of Tehuantepec, Geofis. Int., 42(1), 101-114.

Umatani, S., and T. Yamagata (1991), Response of the eastern tropical Pacific to meridional migration of the ITCZ: The generation of the Costa Rica Dome, J. Phys. Oceanogr., 21, 346-363, doi:10.1175/1520-0485 (1991) $021<0346$ :ROTETP $>2.0$. CO;2.

Uppala, S. M., et al. (2005), The ERA-40 re-analysis, Q. J. R. Meteorol. Soc., 131, 2961-3012, doi:10.1256/qj.04.176.

Welch, P. D. (1967), The use of fast Fourier transform for the estimation of power spectra: A method based on time averaging over short, modified periodograms, IEEE Trans. Audio Electroacoust., 15, 70-73, doi:10.1109/TAU.1967.1161901.

Wentz, F. J., and D. K. Smith (1999), A model function for the ocean-normalized radar cross section at $14 \mathrm{GHz}$ derived from NSCAT observations, J. Geophys. Res., 104, 11,499-11,514, doi:10.1029/98JC02148.

Wentz, F. J., C. Gentemann, D. Smith, and D. Chelton (2000), Satellite measurements of sea surface temperature through clouds, Science, 288 847-850, doi:10.1126/science.288.5467.847

Willett, C. S., R. R. Leben, and M. F. Lavín (2006), Eddies and tropical instability waves in the eastern tropical Pacific: A review, Prog. Oceanogr., 69, 218-238, doi:10.1016/j.pocean.2006.03.010 
Wyrtki, K. (1966), Oceanography of the eastern equatorial Pacific Ocean, Oceanogr. Mar. Biol. Annu. Rev., 4, 33-68.

Xie, S. P., H. Xu, W. S. Kessler, and M. Nonaka (2005), Air-sea interaction over the eastern Pacific warm pool: Gap winds, thermocline dome, and atmospheric convection, J. Clim., 18, 5-20, doi:10.1175/JCLI-3249.1.

Xie, S. P., C.-H. Chang, Q. Xie, and D. Wang (2007), Intraseasonal variability in the summer South China Sea: The wind jet, cold filament, and recirculations, J. Geophys. Res., 112, C10008, doi:10.1029/2007JC004238.

Yoshida, S., B. Qiu, and P. Hacker (2010), Wind-generated eddy characteristics in the lee of the island of Hawaii, J. Geophys. Res., 115, C03019, doi:10.1029/2009JC005417.
Zamudio, L., H. E. Hurlburt, E. J. Metzger, S. L. Morey, J. J. O’Brien, C. Tilburg, and J. Zavala-Hidalgo (2006), Interannual variability of Tehuantepec eddies, J. Geophys. Res., 111, C05001, doi:10.1029/ 2005JC003182.

Zhang, C. (2005), Madden-Julian Oscillation, Rev. Geophys., 43, RG2003, doi:10.1029/2004RG000158.

Zhuang, W., S.-P. Xie, D. Wang, B. Taguchi, H. Aiki, and H. Sasaki (2010), Intraseasonal variability in sea surface height over the South China Sea, J. Geophys. Res., 115, C04010, doi:10.1029/2009JC005647. 